Viviani, M., Glisic, B. and Smith, I.F.C. "Separation of thermal and autogenous deformation at varying temperatures using optical fiber sensors" Cement and Concrete Composites, Vol 29, No 6, 2007, pp 435-447.

\title{
Separation of thermal and autogenous deformation at varying temperatures using optical fiber sensors
}

\author{
M. Viviani ${ }^{1, *}$, B. Glisic ${ }^{2}$, I.F.C. Smith ${ }^{3}$
}

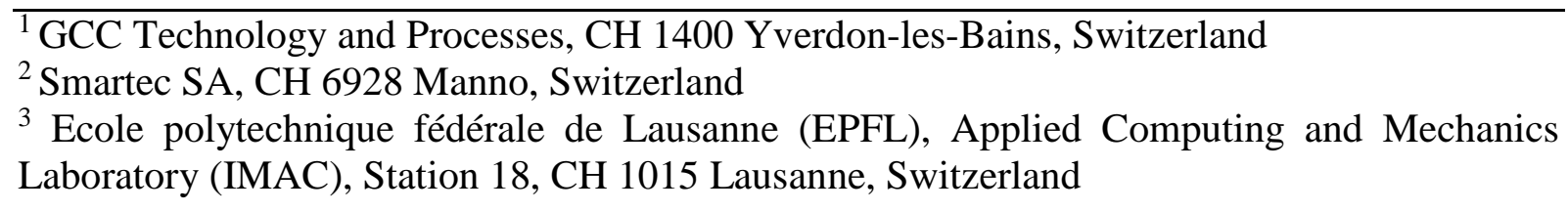

\begin{abstract}
Common, high and ultra high performance concretes undergo autogenous deformation (AD) when hardening. Deformations are often measured in specimens cured in so-called autogenous conditions, where fully coupled thermal deformation (TD) and AD are the only deformations. Therefore, in autogenous conditions, a decoupling technique must be used to separate the contributions of TD and AD. This paper presents a new technique using optical fiber sensors in specimens that are cured at varying temperatures and in autogenous conditions. Degree of reaction indexes (DRI), sometimes called maturity and equivalent time, are employed to separate TD and AD. The paper begins with a summary of the application of DRI to decoupling techniques, with particular focus on theoretical limits and potential for deformation separation. Current practices related to decoupling and modeling of the thermal and autogenous deformation are evaluated through comparison with experiments. Results confirm that testing improves the accuracy of estimation of values for the thermal expansion coefficient (TEC). Moreover, since AD swelling is detected for all tests, models that include the assumption that $\mathrm{AD}$ is exclusively shrinkage are not appropriate for describing $\mathrm{AD}$ at varying temperatures.
\end{abstract}

Keywords: Arrhenius, maturity separation of effect thermal expansion coefficient, autogenous deformation fiber optic sensors, concrete

\section{Introduction}

Total deformation of specimens cured in "autogenous conditions" is the sum of thermal and autogenous deformation (TD and $\mathrm{AD}$ ). If the temperature of hydration is kept artificially constant, $\mathrm{AD}$ and total deformation are equivalent since there is no thermal deformation. Many systems have been proposed to measure AD directly and its evolution has been measured for a range of cement based materials. It is not clear whether it is appropriate to apply time evolutions of AD obtained from specimens that are cured at constant temperature to results from other specimens that are hydrating at varying temperatures.

Concrete hydration, as all hardening reactions, is proposed by many authors to be treated as a classic thermo-chemical process. In the case of hardening materials, reactants become a product through a change of state (from liquid to solid). The rate of the chemical reaction $r$ is expressed in term of its rate of reaction:

$$
\mathrm{r}=\frac{\mathrm{dg}}{\mathrm{dt}} \quad \text { Eq.1 }
$$

Where $\mathrm{g}$ is the increase in concentration of products, expressed in mole/dm ${ }^{3}$ and $\mathrm{t}$ is time 
The Arrhenius Law states that the rate of a chemical reaction increases exponentially with the absolute temperature, regardless of the degree of reaction obtained according to [1]

Maturity methods should not be confused with the single word, maturity. Maturity methods are non-destructive testing approaches [2]. Degree of reaction indices, DRI (true degree of reaction is often indirectly evaluated and thus substituted with other indices) are used within maturity methods. The best means for expressing the evolution of a property as a function of a degree of reaction index would be to test both the degree of reaction and the property at any time.

The advancement of hydration is computed by DRIs. The most commonly used DRIs, such as equivalent time, are determined from empirical formulas (for example, Freiesleben [3]). More generally, the evolution of percentage gain of a property $\mathrm{P}(\mathrm{t})$ (i.e. $\mathrm{P}_{(\mathrm{t})} / \mathrm{P}_{(\mathrm{t}=\infty)}$ of the tested material) has been observed to be linearly related with the degree of reaction [4] for properties such as chemical shrinkage, compressive strength and heat of reaction.

A DRI can most easily replace the degree of reaction if there is a linear relationship that links the two parameters. Schindler, in a recent article, shows that the equivalent age concept is suitable to be a DRI [5] since it shows linearity at any age with degree of reaction [6]. While the equivalent time might be less representative at very early age than other indices, using appropriate techniques for determining the initial time $t_{0}$, see $[6,7,8,9]$ and the activation energy (see [6]), gives this measure the potential to be a simple and effective DRI. Maturity is historically very important [10] and has been shown to be conceptually coincident with the equivalent time [11].

If the TEC and AD evolution are observed to be closely related to the evolution of the DRI, regardless of the combination of time and temperature (variations in the temperature of hydration modify the speed of reaction only), then the Arrhenius concept applies to these quantities. In this case AD and TEC can be considered to be physical properties of concrete such as the compressive strength. Some attempt to determine the relations that link DRI, AD and TEC has been made in literature.

Recent articles show that AD is linearly related to the decrease of $\mathrm{RH}$, although at very early age this relation is not well established. [7, 12, 13, 14, 12, 15]. Furthermore, trends in RH values are believed to be indicators of the hydration process development.

Other authors show comparisons between DRI histories of AD measured within specimens hydrating under different constant temperatures. The conclusion often drawn is that these histories are very similar, and if an appropriate choice of the initial time $t_{0}$ is made, the evolutions are the same $[16,17,7,15,18]$. However limitations of temperature are given by various authors and theoretical limitations are examined [18]

Finally, authors compared DRI histories of AD measured within specimens hydrating under constant and varying temperatures. The heating-cooling regime can change the mechanisms of water transport, thus modifying the AD. The TEC appears to be less sensitive to the curing regime than the $\mathrm{AD}$. The degree of pore saturation is likely to be changed by the reabsorption of the bleeding water that change accordingly to the temperature regime used [19, 20]. Furthermore the TEC is shown not necessarily to be an instant weighted average of the TEC of the initial compounds and the products of reaction [17, 21, 22, 23, 9]. 
Expansion phases of AD at very early and early age are object of many studies [24]. They are source of uncertainty for the predictive models of $\mathrm{AD}$ and the principal difference between the DRI evolution of $\mathrm{AD}$ carried out in specimens cured at constant temperature and in specimens with heating-cooling cycles. Despite a lack of information, some authors proposed a theory to explain the AD expansions $[20,13,24]$. These theories are connected with the degree of pore saturation, the redistribution of bleeding water and the cooling temperature for AD.

At very early age, the reabsorpion of bleeding has an effect on AD. Bleeding water lies on the surface of the concrete pours unused by the hydration process. If a situation is created such that the reaction "needs" more water, a transport phenomena is created and the bleeding water is reabsorbed during first hours after pouring [19]. The refilling of the pores with water causes an augmentation of the pressure in the pores, diminishing or eliminating the mechanism underlying the autogenous shrinkage and creating $\mathrm{AD}$ swelling. This is consistent also with research on the effect of early w/c variation. In these kinds of tests, the effect of a small w/c variation due to addiction of water in order to keep constant the slump of the pour resulted in a porosity variation and in a consequent strength variation. Thus, a small (and transitory) change in the w/c ratio (such as in the bleeding phase) might have important influence upon the hydrate arrangement at very early age as well as upon moisture transport.

At early age and especially for w/c ratios higher than 0.40 , autogenous swelling systematically take place. This is believed to be connected with the thermally induced swelling that takes place in the cooling phase [20]. No other evidence has been found to explain this phenomenon. This mechanism is influenced by the type of the curing regime and not by the temperature of the hydration. DRI-AD evolutions obtained with curing at different constant temperatures are very similar, while those obtained with different heating-cooling regimes can be different.

Furthermore, cooling provokes an expansive phase of $\mathrm{AD}$, while the TEC remains largely unaltered. TEC can also be influenced by anomalous thermal expansion of the water in cementitious materials. However; these changes are seen to be connected with the packing of the water in pores and the ion content, and thus associated with the advancement of hydration and changes in the cement chemistry.

From the evidence provided by the authors cited above, for moderate temperature ranges and for similar shapes of curing regimes, Arrhenius concepts apply also to AD. Furthermore the results indicate that Arrhenius concepts apply to the TEC, regardless of the curing regime. The last statement is important for assessing the correctness of the separation procedures used at varying temperatures. Finally, the TEC, determined by subtracting from the total deformation the $\mathrm{AD}$ obtained at constant temperature, is affected by the same incertitude underlying the non-systematic behavior of $\mathrm{AD}$ evolution carried out at varying temperatures.

This paper presents a new technique using optical fiber sensors in specimens that are cured at varying temperatures and in autogenous conditions. Degree of reaction indexes are employed to separate types of deformations. The next sections describe experimental details and this is followed by a description of the methodology used. The paper ends with a discussion of the results and opportunities for further work. 


\section{Testing apparatus and materials.}

When separating AD and TEC using a DRI, thermodynamic parameters may need to be determined in accordance with the DRI that is adopted. For the results presented in this paper, the Freiesleben and Pedersen [3] model is used:

$$
E_{t}=\int_{t_{0}}^{t}\left[\exp \frac{-E_{a}}{R}\left(\frac{1}{T(t)}-\frac{1}{T_{\text {reference }}}\right)\right] d t \quad \text { Eq. } 2
$$

where: $E_{t}$ is the equivalent age; $t$ is the elapsed time; $T_{\text {reference }}$ is the reference temperature (while it is often $20^{\circ} \mathrm{C}$ in European countries, $23^{\circ} \mathrm{C}$ is used in the USA); $\mathrm{T}(\mathrm{t})$ the temperature of the specimen; $E_{a}$ is the activation energy; $R$ is the gas constant and $t_{0}$ is the time at the end of pouring

Thus, the fundamental parameter is the activation energy Ea. The strategy adopted for determining the activation energy and following the TEC and AD DRI-evolution, uses two specimens of the same type of concrete. Both specimens have the same dimensions. They are monitored with a stiff and a soft sensor. These sensors are fiber-optic deformation sensors Aside from their stiffness; each pair of sensors has the same features. One specimen is wrapped with glass wool. The glass wool acts as insulation and keeps the temperature of this specimen at a higher level than the temperature of the other specimen. This induces a higher rate of reaction in the insulated cylinder. The temperature is measured in both specimens (see Fig. 1 and 2).

\section{Dimension of specimens and sensors}

The dimension of specimens must be appropriate for the material under study. In composite materials, the controlling parameter is the diameter (or equivalent diameter) of the largest component (see Figure 3, [25]). For example, in concrete this is the maximum diameter of the aggregate. An approximate rule states that the mould wall influences concrete behavior for a distance that is equivalent to three times the maximum diameter of the aggregate. Sensors must be placed out of this perturbed zone.

The use of an optical sensor of the type employed in this study [26, 27] requires a gauge length longer than $400 \mathrm{~mm}$ to obtain reliable results. This is because the average strain resolution of the sensor is dependent on the gauge length and thus inaccuracies are reduced by increasing the gauge length. The dimensions of the specimens were fixed according to these constraints. More details are given in the following Section.

\section{Specimen and sensor characteristics}

The mould dimensions and materials used in this study are:

M1 Cylinders Ø $160 \mathrm{~mm}$ and height $600 \mathrm{~mm}$, plastic-coated paper-box;

M2 Cylinders Ø $315 \mathrm{~mm}$ and height $1000 \mathrm{~mm}$, plastic pipes (standard for water reticulation) (see Figure 4);

M3 Boxes $550 * 400 * 70$ mm, wood panels (see Figure 5); 
Mould M2 was used because the early apparatus (sensors included) was single-use. Development of new and reusable sensors reduces the time and cost of a test. This motivated design of a mould in which sensors are reusable. The most convenient shape was the box (M3).

Mould M1 was tried once for comparison with Mould M2, even though it did not fit the specification related with the perturbed zone [28]. Mould M3 was used for a test in a thin layer of special repairing mortar made of high performance fibre-reinforced cement-based material (UHPFRC) [29]. The testing of this material posed particular challenges. It is usually cast in very thin layers (down to $15 \mathrm{~mm}$ ) and poured directly into the moulds. It is selfcompacting and highly viscous, so that the only way to cast it is to pour it directly from a carrier. It was not possible to spoon it into a mould. As soon as the hydration began, the bolts were unscrewed to reduce constraining them (see Figure 5). Characteristic of the external pipe of sensor are given in Table 1

\section{Mould M2 characteristics}

The use of large cylindrical moulds is uncommon because the cylinders are difficult to manufacture with materials such as wood or plastic. However, the large range of pipes for water drainage provides an opportunity to make large moulds because the pipes are made of high quality frictionless materials (PVC), are easy to cut and weld, and are relatively cheap. For this reason, a study of Mould M2 was performed. Optical sensors were glued to the surface of the plastic cylinders vertically and on the diameter, see Figure 6 [28]. Measuring these deformations enables assessment of the behavior of the mould relative to the material inside it.

In PVC pipes, the thermal expansion coefficient can easily reach $40 \mu \varepsilon /{ }^{\circ} \mathrm{C}$. Thus, the rise of temperature might make the mould expand more than the inside material, leading to settlement of the material. As the temperature falls, the mould would regain its initial shape and constrain the settled material, which meanwhile would have developed a lower thermal expansion coefficient. Measurements showed that the influence of such an effect is negligible.

\section{Deformation and temperature measurement.}

Sensors provide the time history of the total deformations in the specimens as well as the kinetic parameters associated with the mix design. The methodology adopted for determining the kinetic parameters is explained elsewhere [28, 30] and is based on early age deformation measurements of stiff and soft sensors. Details of the testing apparatus are also available elsewhere [31]. With the knowledge of values for activation energy, it is then possible to express deformation histories in terms of the degree of hydration. Measurement errors were estimated for deformations and temperature. Noise of deformation and temperature, and drift of deformation must be taken into account when values for deformation and temperature are added, subtracted, multiplied and divided. Propagation of errors has been made in order construct the error envelope for the TEC and for AD.

The curing condition shown in Figures 1 and 2 is autogenous. Thus the total deformation measured on the specimen S1 and S2 is the sum of autogenous and thermal deformations. The deformations in these specimens, once converted in terms of equivalent time (DRI), are expressed as follows:

$$
\varepsilon_{1}\left(\mathrm{E}_{\mathrm{t}}\right)=\varepsilon_{\mathrm{ad}}\left(\mathrm{E}_{\mathrm{t}}\right)+\operatorname{TEC}\left(\mathrm{E}_{\mathrm{t}}\right) * \Delta \mathrm{T}_{1}\left(\mathrm{E}_{\mathrm{t}}\right) \quad \mathrm{Eq} .3
$$




$$
\varepsilon_{2}\left(\mathrm{E}_{\mathrm{t}}\right)=\varepsilon_{\mathrm{ad}}\left(\mathrm{E}_{\mathrm{t}}\right)+\mathrm{TEC}\left(\mathrm{E}_{\mathrm{t}}\right) * \Delta \mathrm{T}_{2}\left(\mathrm{E}_{\mathrm{t}}\right) \quad \text { Eq. } 4
$$

where: TEC is the thermal expansion coefficient, $\Delta \mathrm{T}_{1}$ is the rise in temperature from the initial time, specimen $1 ; \Delta T_{2}$ is the rise in temperature from the initial time, specimen $2, \varepsilon_{a d}$ is the autogenous deformation; $\varepsilon_{1}$ is the total deformation measured in specimen 1 , $\varepsilon_{2}$ is the total deformation measured in specimen 2 and $E_{t}$ is the equivalent time of the concrete

Equations 3 and 4 have two unknowns: TEC and $\mathrm{AD}\left(\varepsilon_{\mathrm{ad}}\right)$. Their values are determined by elimination. Figure 7 shows how the TEC is calculated. Total deformation and hydration temperature histories measured in specimens S1 and S2 (see Figure 1 and Figure 2) are converted into equivalent time histories. Then, at any equivalent time the two temperature histories and the two deformation histories are subtracted. The ratio at any equivalent time between the delta deformation and the delta temperature is the thermal expansion coefficient (see Figure 7). This procedure is based on the hypothesis that the Arrhenius rate theory applies to the TEC.

Once the thermal expansion coefficient is obtained in terms of equivalent time, it is inserted into Equation 3. Figure 8 illustrates the use of Equation 4 to decouple values of autogenous deformation. The equivalent time evolutions of deformation, temperature and thermal expansion coefficient are used. In this example, specimen S1 (Figures 1 and 2) is used. The product of TEC and temperature of specimen S1 is made at any equivalent time to obtain the thermal deformation. Then, from the total deformation, the thermal deformation is subtracted. Since the specimen S1 is cured in autogenous conditions (only thermal and autogenous deformation), the result of such subtraction is the autogenous deformation.

Five types of cement-based material were tested (see Table 2). Concretes that are commonly used in civil engineering were made with different aggregates. Air entrainers were used in Test 1 making it the same concrete used for a long existing tunnel in Europe. Super plasticizers were also used. Test 5 contains a high quantity of plasticizer. Silica-fume powder was also used in that Test 5 [29], Test materials contained low quantities of Portland cement in some cases (see Table 2).

All materials have different hardening behaviours. As mentioned previously, different proportions and quality of concrete components lead to various hardening reactions. The goal of testing a number of mixes is to study aspects of hardening reactions on a variety of cementbased materials.

\section{Results and discussion}

Data have been reduced so that decoupling of effects is carried out using the procedure explained in the previous section. The shapes of the experimental TEC evolution are non linear, with high values at the beginning and a levelling-off after few hours as proposed by Byfors [9], see Figure 9. Autogenous deformation is shrinkage only when the rate of thermal deformation gain is more than the rate of total deformation gain. This means that the product of the TEC and the rise in temperature is more than the total deformation at an equivalent time (see Equation 3, Figure 8), and this does not happen for all environmental situations and all types of concrete.

A conclusion is that $\mathrm{AD}$ might assume negative values (expansions) especially when concrete cools and when the increase of temperature slows. Autogenous expansion can then be protracted in time since the temperature levels to a constant value (ambient temperature). If 
the wrong TEC is used in separation, swelling might be overlooked and measures taken to accommodate high shrinkage values might be inappropriate. .

The literature review has identified two typical shapes for TEC evolutions. The first shape is described by Byfors [9] and Laplante [22] to be a rapid decrease of the TEC in the first 10 equivalent time hours, then a leveling off to the TEC values typical of mature concrete (5-12 $\mu \mathrm{m} / \mathrm{m} /{ }^{\circ} \mathrm{C}^{-1}$ ) at around 10 to 15 equivalent time hours. Figure 10,11 and 12 shows the TEC evolution for Tests 2 to 4 . TEC evolutions are similar to the one proposed by Byfors and Laplante, with the difference that the time of TEC leveling-off is of 55 hours for Test 2 (see Figure 10) and 30 for Tests 3 and 4 (see Figures 11 and 12). The second shape for TEC evolutions includes a minimum value before TEC levels off $[19,23]$. These shapes are observed for Test 1 (see Figure 9). The leveling-off time of TEC at about 60 hours observed in Test 1 (see Figure 9) is consistent with the findings of Bjøntegaard, [19] and Shimasaki [23].

A new kind of TEC evolution is called "apparent". The particularity of such TEC evolution is that grows from zero to higher values in the first hours of the hydration (see Figure 13). This might be the effect of long induction periods ( $>20$ hours). Similar results have been obtained by [32] for three ultra-high performance concretes (heated and non-heated).

Measurement errors have been estimated for deformations and temperatures using experimental observations. Measurement noise when reading deformation and temperature as well as time dependent drift are especially important when deformation and temperature readings are added, subtracted multiplied or divided since errors can amplify to become high percentages of results that are reported. Propagation of errors has been estimated in order construct the error envelope (approximately two standard deviations from mean) for values of TEC and autogenous deformation. The error, $\Delta s$, for addition and subtraction of quantities $A$ and B is calculated as follows:

$$
\Delta \mathrm{s}=\sqrt{\Delta \mathrm{A}^{2}+\Delta \mathrm{B}^{2}} \text { Eq. } \quad 5
$$

Where: $\Delta \mathrm{s}$ is the error related to results of addition or subtraction of quantities $\mathrm{A}$ and $\mathrm{B}, \Delta \mathrm{Ais}$ the error related to measuring quantity $\mathrm{A}, \Delta \mathrm{B}$ is the error related to measuring quantity $\mathrm{B}$

For multiplication and division of quantities A and B the error is calculated as follows:

$$
\Delta \mathrm{r}=\sqrt{\left(\frac{\Delta \mathrm{A}}{\mathrm{A}}\right)^{2}+\left(\frac{\Delta \mathrm{B}}{\mathrm{B}}\right)^{2}} \quad \text { Eq. } 6
$$

Where $\Delta \mathrm{r}$ is the error related to results of multiplication or division of the quantities $\mathrm{A}$ and $\mathrm{B}$

The error envelope, calculated on the basis of the maximum possible error from measurement, shows that the errors have little effect on values of the TEC and AD.

Activation energy is determined using a new methodology that is based on measurements of temperature and deformations [33, 30]. The hardening curve (the difference between the soft and stiff sensors' deformation-time history) is calculated and divided by the temperature variation-time history. The resulting graphs have a curve that begins with a steep increase and then levels off to a constant value (see Figure 14). Later, a delta temperature or deformation 
approaching zero produces a vertical asymptote. The point at which a line drawn on the plateau of the $\frac{\Delta \varepsilon}{\Delta T}$ curve departs from the curve on the left side is called equivalency point.

The equivalency point is assumed to indicate a certain degree of reaction. This assumption is made on the basis of the mechanism of deformation transfer between the hardening material and sensors. This means that at the equivalency point, the degree of reaction is the same for all specimens of the same material, hydrating in autogenous conditions, independent of the combination of time and temperature that has lead to such a point.

Determination of Ea requires detection of the equivalency point in two specimens made of the same hardening material and reacting at different speeds (see Figure 1). In two cylinders, the hardening material of a same pour is hardening in autogenous conditions (only thermal and autogenous deformation). Both the specimens are protected against drying by means of plastic sheets. Temperature and deformation measurements of the two specimens are inserted in Equation 4. For each specimen, the integral is calculated to the time of occurrence of the equivalency point. Because $E_{t}$ at the equivalency point is assumed to be the same for both specimens, Ea can be determined. Errors in the determination of the equivalency point might result in poor predictions of activation energy. Drift and noise related to measurements introduce an error in terms of time on the equivalency point. The worst case scenario for the calculation of the activation energy corresponds to the following bounds on values for the equivalency points (Ep):

$$
\mathrm{Ep}=\mathrm{Ep} \pm 6 \text { minutes }
$$

This leads to two values for bounds on the range of possible values for the activation energy. The worst case scenario on the value for the activation energy has been considered. The variation of the activation energy has an effect on values calculated for TEC and AD. Although this effect can be important, it is not enough to change the observations and conclusions that are drawn from the data in this paper. The effect of the activation energy variation in TEC is shown in Figure 15 (worst case observed) and Figure 16 (an average case).

For separating values for $\mathrm{AD}$, knowledge of the TEC is necessary. It is common practice to use a constant thermal expansion coefficient. This approach may lead to large errors in the evaluation of values for AD. Other authors believe that assuming a constant value for TEC is more robust than determining the thermal expansion coefficient using isothermal $A D$ measurements. The evolutions of values for the TEC for five cement-based materials (see Table 1) have been used to separate values for AD.

The zero AD is chosen to be the final setting time. Final setting time has been evaluated to be when the degree of reaction is $\alpha=0.26$ (w/c) for slag cements and silica fume incorporation in the mix while for the other cement types zero AD is set at $\alpha=0.40$ (w/c), as presented in [34, 9 and 35]. Values for final setting time are presented in Table 3. The degree of reaction evolution of each test has been estimated using a new predictive technique presented elsewhere [33, 30], which allows prediction of the compressive strength-DRI relationship using early age deformation and strength data (measured in the first three days). The estimation of the errors justifies good quality estimations of the equivalent time at the setting time. The initial time $t_{0}$ is matter of much debate, and more measurements are likely to improve the possibility of having new models and techniques to link this parameter to the thermodynamics of the compounds used in the mix $[8,34]$ 
Separated AD of Test 1 is characterized by a first phase of shrinkage that ends at around 30 hours and is followed by a zone of shrinkage that lasts for another 10 hours (see Figure 17). Then, a zone of small, steady swelling appears. Tests 2 has an initial period of shrinkage (ends at 15 hours, see Figure 18), while Test 5 has a very small initial shrinkage that ends at 8 hours (see Figure 19). Tests 2 to 5 have a swelling phase that ends at 80 hours for Test 1-3 and levels off at 40 hours for Test 4 . Values from Test 5 could be monitored for only 32 hours. At that time AD swelling was leveling (see Figure 19).

The same calculation made using the evolution of TEC shown in Figures 9 to 13 are repeated using a constant TEC (of $12 \mu \mathrm{m} / \mathrm{m}^{\circ} \mathrm{C}^{-1}$ ), with surprising results. In the first hours of the cement-based material life, $\mathrm{AD}$ can be an expansion. Using constant values for TEC on the calculation, AD expansion appears only in Test 1 and 3, lasting a few hours (see Figure 17 and 20, dashed line) while using the experimentally determined TEC, expansion occurs in all tests (see Figures 17-21, continuous and dotted lines). In Test 2, 4 and 5, the AD is separated using constant value of TEC of $12 \mu \mathrm{m} / \mathrm{m}^{\circ} \mathrm{C}^{-1}$. Values for AD are shrinkage only (see Figures 18, 19 and 21, dashed lines)

In Test 5, a direct comparison of AD with an isothermal test is made. The concrete of Test 5 (see Table 2) is a newly developed UHPFRC. The AD has been tested by Habel [29] using a new apparatus developed at the University of Laval by Charron [36] at constant temperature. The shapes of the two curves are the same when the experimental values for TEC are used and completely different when the constant value TEC is used. The effect of the Activation energy variation in $\mathrm{AD}$ is shown in Figure 22 (worst case observed) and Figure 23 (an average case).

\section{Conclusions}

A practical method for determining the thermal expansion coefficient is proposed. The values of TEC obtained are consistent with those reported in the literature. TEC results are used to separate values for autogenous deformation from the total deformation. Calculated values for indicate expansions in some cases. Expansion can last for 80 hours (equivalent time at $20^{\circ} \mathrm{C}$ ). Although the propagation of worst case scenarios for errors (on measurements and activation energy values) might lead to errors in values for AD and TEC, they are not enough to change the form of the curves. Thus, the following three conclusions are drawn:

1. The heating-cooling curing regime causes AD swelling during the cooling phase and this lasts until the temperature levels off.

2. Values for the TEC should be determined experimentally rather than, for example, assumed to be constant over the early age phase of concrete hardening.

3. Models of the evolution of $\mathrm{AD}$ for constant hydration temperature must be adapted to varying temperatures if they cannot accommodate $\mathrm{AD}$ swelling. At varying temperatures, expansions are likely to appear for w/c higher than 0.40 . This swelling may last for much of the cooling phase of concrete.

These conclusions are based on the assumption that the Arrhenius concept is valid for AD evolutions under varying temperature. Since this has not yet been established conclusively, further study is necessary before $\mathrm{AD}$ evolution models can be proposed for varying temperature. 


\section{Acknowledgments}

This project was supported in its early stages through a project funded by the Swiss Commission for Technology and Innovation (CTI) and Cemsuisse (Swiss Cement Fabricators Association). The authors are grateful to Professor Karen Scrivener, EPFL, for valuable advice and for providing testing support. We also express special thanks to Patrice Gallay who has helped design and build testing apparatus. 


\section{References}

[1] Arrhenius S, On the reaction velocity of the inversion of cane sugar by acids. Zeitschrift für Physikalische Chemie 1889;(4):226-232. As translated and published in Margaret H. Back \& Keith J. Laidler, "Selected Readings in Chemical Kinetics." Pergamon, Oxford 1967.

[2] Carino NJ, The maturity method. In: CRC handbook of non-destructive methods, CRC Press, Boca Raton, USA, Chapter 5, 1991, p. 101-146.

[3] Freiesleben Hansen P and Pedersen J, Maturity computer for controlled curing and hardening of concrete. In: Nordisk Betong, 1977; 1:19-34.

[4] Geiker M, Studies of portland cement hydration by measurements of chemical shrinkage and systematic evaluation of hydration curves by means of the dispersion model. PhD Thesis, Lyngby, Technical University of Denmark, 1983.

[5] Freiesleben Hansen P and Pedersen J, Curing of Concrete Structures CEB Information Bulletin 166, 1985. p. 42.

[6] Schindler A. Effect of temperature on the hydration of cementitious materials. ACI Materials J 2004;101(1):72-81.

[7] Mounanga P Baroghel-Bouny V Loukili A Khelidja A, Autogenous deformations of cement pastes: Part I. Temperature effects at early age and micro-macro correlations. Cement and Concrete Research 2006;6(1):110122

[8] Weiss WJ. Experimental determination of the 'Time-Zero'. In: Early Age Cracking In Cementitious Systems RILEM State of the Art Report TC-EAS, ed A. Bentur, 2002 p.193-195.

[9] Byfors J. Plain concrete at early ages. Stockholm: CBI Research, Swedish Council For Building Research, 1980

[10] Saul A. Principles underlying the steam curing of concrete at atmospheric pressure. Magazine of Concrete Research 1951;2(6):127-140.

[11] De Shutter G. Applicability of degree of hydration concept and maturity method for thermo-visco-elastic behaviour of early age concrete. Cement and concrete composite 2005; 27(6):437-443.

[12] Jiang Z, Sun Z, Wang P. Autogenous relative humidity change and autogenous shrinkage of highperformance cement pastes. Cement and Concrete Research (2006) Article in press

[13] Barcelo L, Moranville M, Clavauda B, Autogenous shrinkage of concrete: a balance between autogenous swelling and self-desiccation. Cement and Concrete Research 2005; 35(1):177-183.

[14] Loukili A, Khelidj A, Richard P. Hydration kinetics, change of relative humidity, and autogenous shrinkage of ultra-high-strength concrete. Cement and Concrete Research 1999;29(4):577-584.

[15] Baroghel-Bouny V, Mounanga P, Khelidjb A, Loukili A, RafaR N. Autogenous deformations of cement pastes Part II. W/C effects, micro-macro correlations, and threshold values. Cement and Concrete Research 2006; 36(1):123-136

[16] Loukili A, Chopin D, Khelidj A, Le Touzo J. A new approach to determine the autogenous shrinkage of mortar at early age considering temperature history. Cement and Concrete Research, 2000;30:915-922.

[17] Turcry P, Loukili A, Barcelo L and Casabonne JM. Can the maturity concept be used to separate the autogenous shrinkage and thermal deformation of a cement paste at early age? Cement and Concrete Research, 2002;32:1443-1450.

[18] Jensen OM and Freiesleben Hansen P. Autogenous deformation and RH-change in perspective. Cement and Concrete Research 2001;31:1859-1865. 
[19] Bjøntegaard Ø. Thermal dilation and autogenous deformation as driving forces to self-induced stresses in high performance concrete. PhD.Thesis. Trondheim, Norway: The Norwegian University of Science and Technology, 1999.

[20] Bjøntegaard Ø, and Sellevold E. Interaction between thermal dilation and autogenous deformation in high performance concrete. Materials and Structures 2001;34(239):266-272.

[21] Kada H, Lachemi M, Petrov N, Bonneau O, Aïtcin PC. Determination of the coefficient of thermal expansion of high performance concrete from initial setting. Materials and Structures 2002;35(245):35-41.

[22] Laplante P, Boulay C. Evolution du coefficient de dilatation thermique du béton en fonction de sa maturité aux tout premiers ages. Materials and Structures 1994;27:596-605.

[23] Shimasaki et alt. Evaluation on Thermal Expansion Coefficient of Concrete at Very Early Ages. In: Mihashi and Wittmann editor. Proceedings of the International Workshop on Control of Cracking in Early Age Concrete, 2002.

[24] RILEM Technical Committee 181-EAS, Report 25 Early Age Cracking in Cementitious Systems. France: RILEM Publications, 1:2002

[25] De Larrard, F. Concrete Mixtures Proportioning: a Scientific Approach, Modern Concrete Technology Series, E\&FN Spon, 1999

[26] Glisic B. Fibre Optic Sensors and Behaviour in Concrete at Early Age PhD Thesis, EPFL, Lausanne

[27] Inaudi, D Fiber optic sensor network for the monitoring of civil engineering structures. PhD thesis, EPFL, Lausanne.

[28] Viviani M, Monitoring and Modeling of Construction Materials During Hardening PhD Thesis No. 3168 (Lausanne Switzerland: EPFL)

[29] Habel K. Structural behavior of elements combining ultra-high performance fibre reinforced concrete (UHPFRC) and reinforced concrete. PhD thesis. Lausanne, EPFL, 2004.

[30] Viviani M, Glisic B, Scrivener KL, Smith IFC. Equivalency Points: Predicting Concrete Compressive Strength Evolution in Three Days. Cement and Concrete Research, Submitted for publication.

[31] Viviani M, Glisic B, Smith IFC. System for monitoring the evolution of the thermal expansion coefficient and autogenous deformation of hardening materials. SPIE, Smart material and structures, 15(6) 2006: N 137

[32] Staquet S, Espion, B. Early-age autogeneous shrinkage of UHPC incorporating very fine fly ash or metakaolin in replacement of silica fume. In: Schmidt, Fehling and Geisenhanslüke editors. Proceedings of the International Symposium on Ultra High Performance Concrete, Kassel: Kassel university press, 2004.

[33] Viviani M, Glisic B, Smith IFC. Three-day prediction of concrete compressive strength evolution. ACI materials J. 2005;102 (4):231-236

[34] Schindler A. Prediction of concrete setting. In: RILEM International Symposium on Advances in Concrete Through Science and Engineering, Evanston, Illinois, March 22-24, 2004.

[35] Pinto RCA and Hover KC. Application of maturity approach to setting times. ACI Materials J., 1999; 96(6):686-691.

[36] Charron, J. P. Contribution à l'étude du comportement au jeune âge des matériaux cimentaires en conditions de déformations libre et restreinte. PhD. Thesis. Laval, Canada, Faculté des études supérieures de l'Université Laval, 2003 


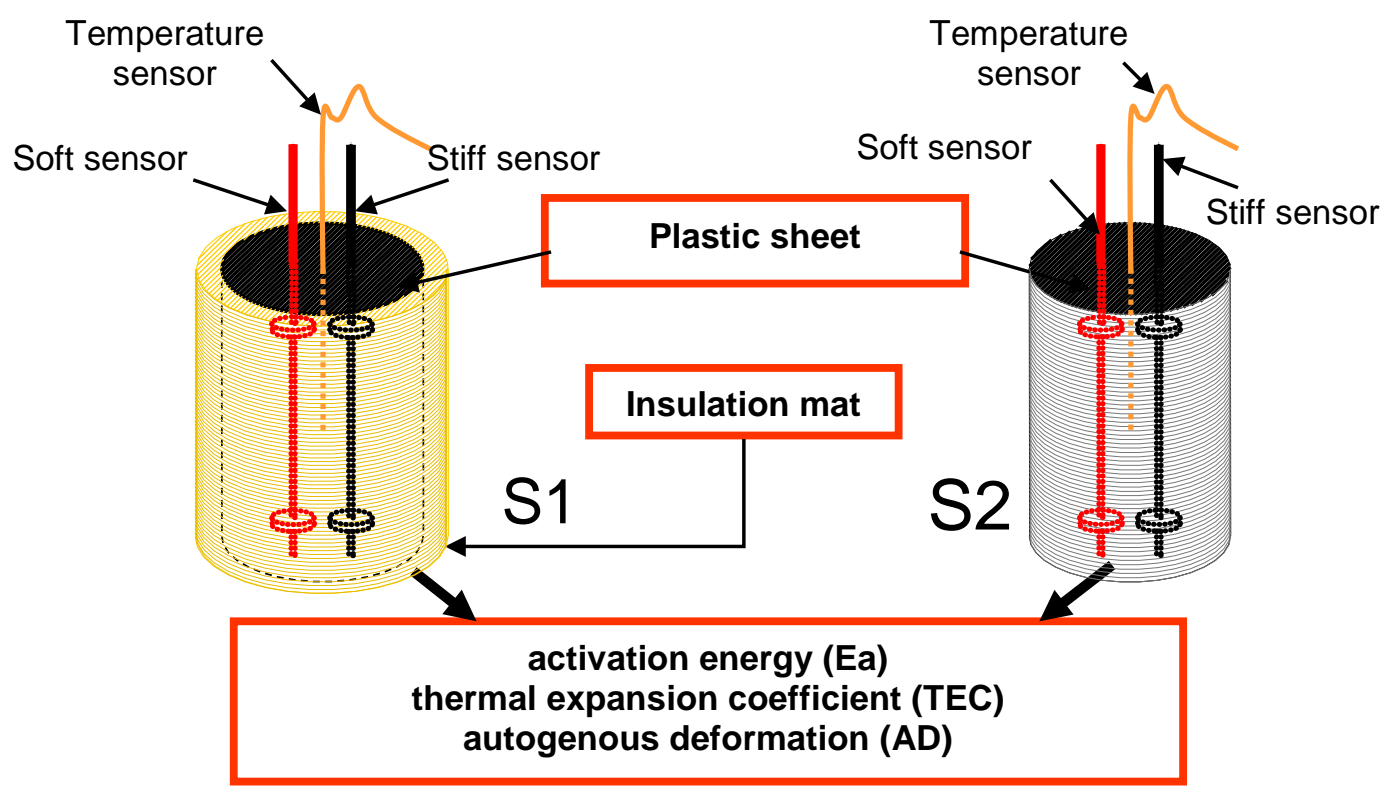

Figure 1 Separation of effects through differently cured specimens

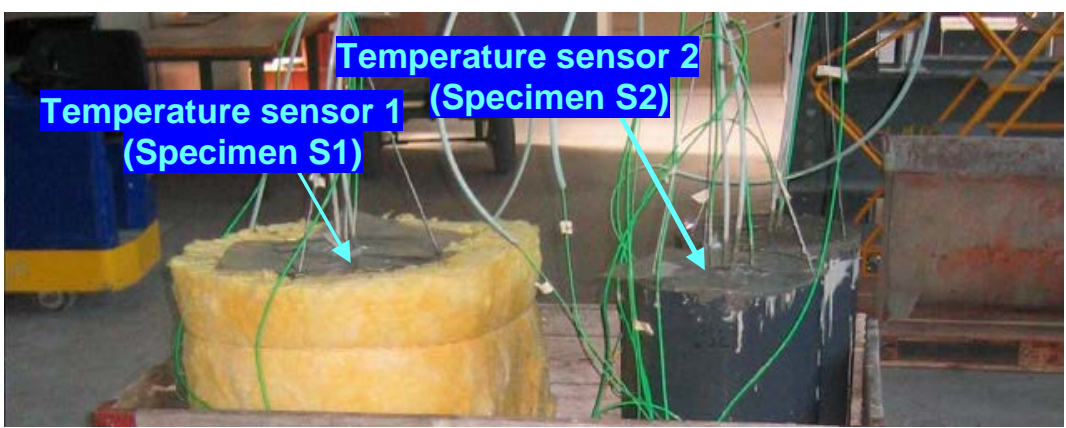

Figure 2 Specimens under test (see Figure 1)

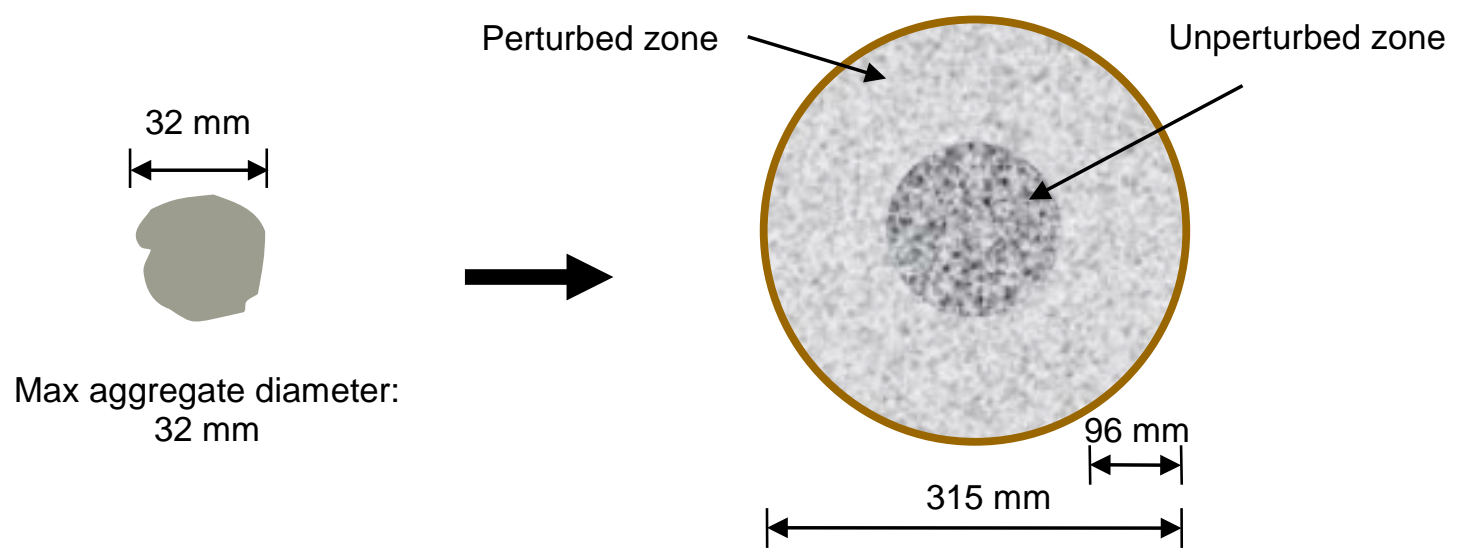

Figure 3 Perturbed zone of a cylindrical specimen (side effect) 

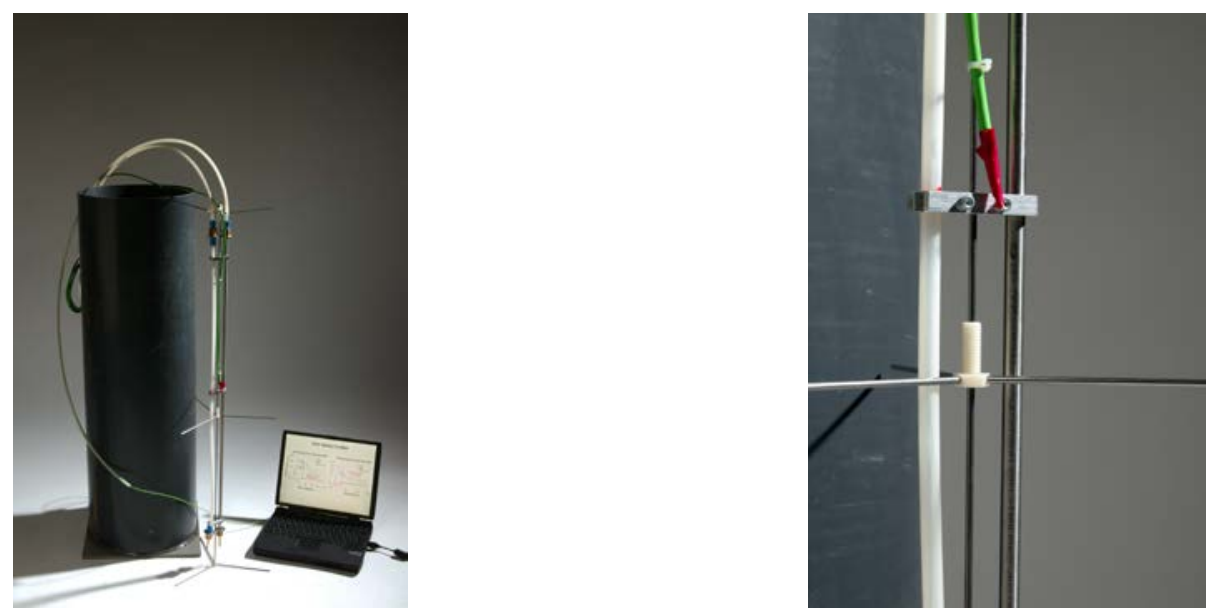

Figure 4 Mould M2 and the positioning apparatus
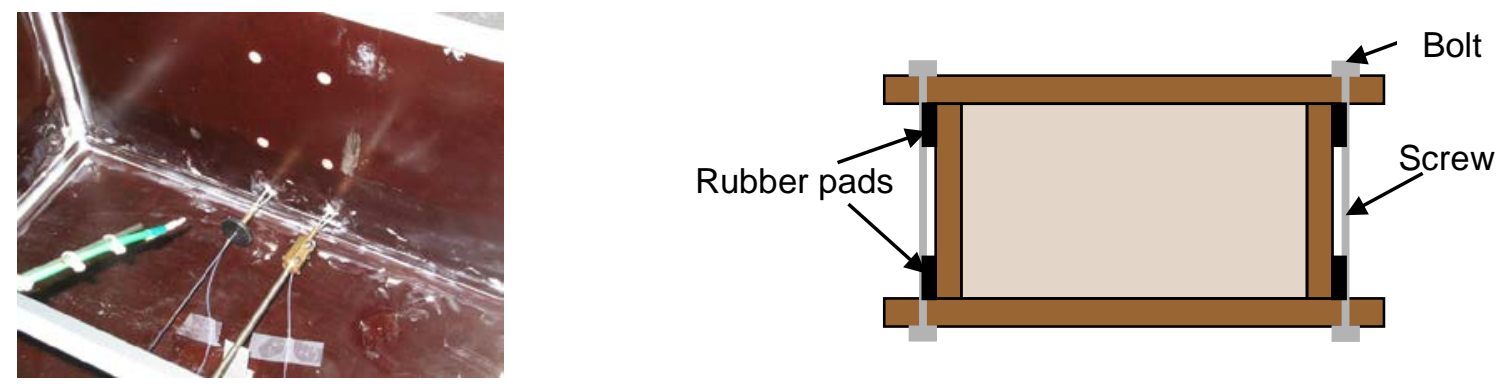

Figure 5 Stiff and soft sensors assembled in Mould M3

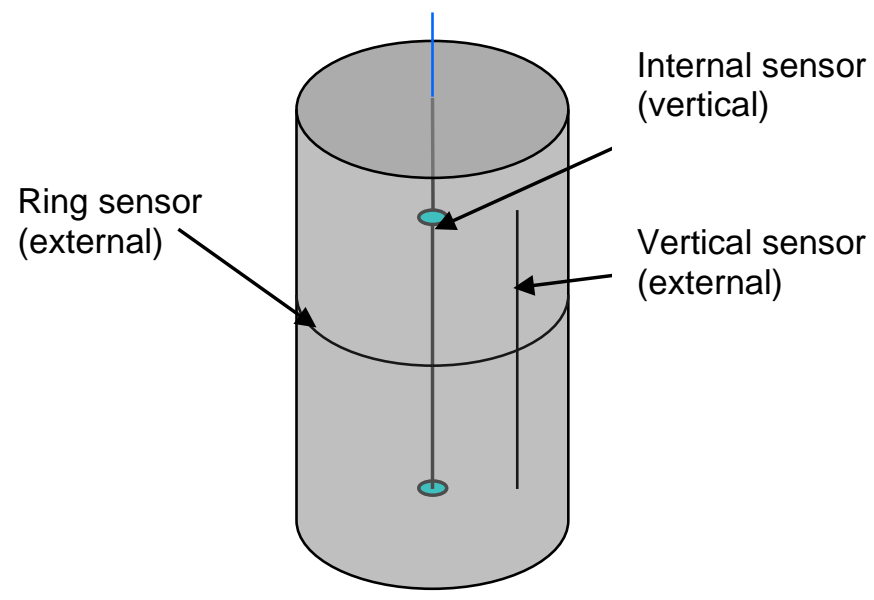

Figure 6 Monitoring of the Mould M2 
Thermo+ Hydro isolated (S1)
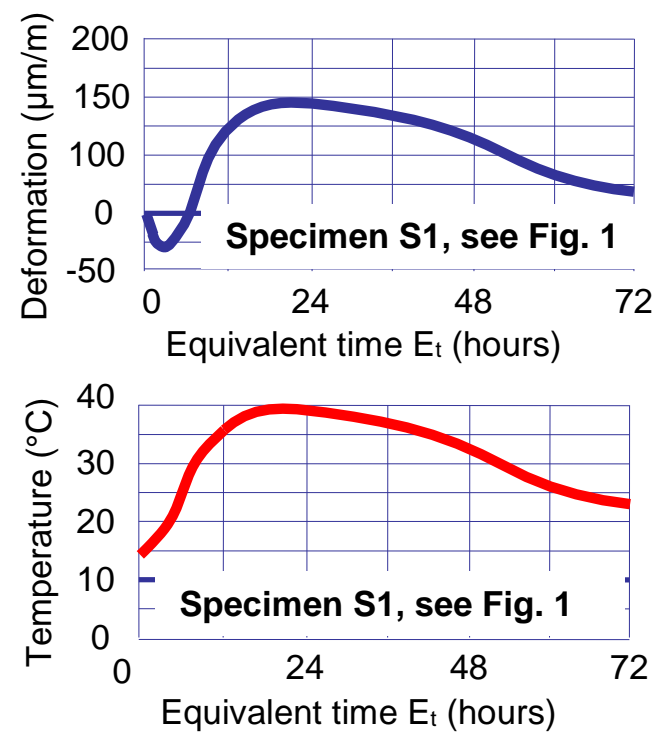

Hydro isolated (S2)
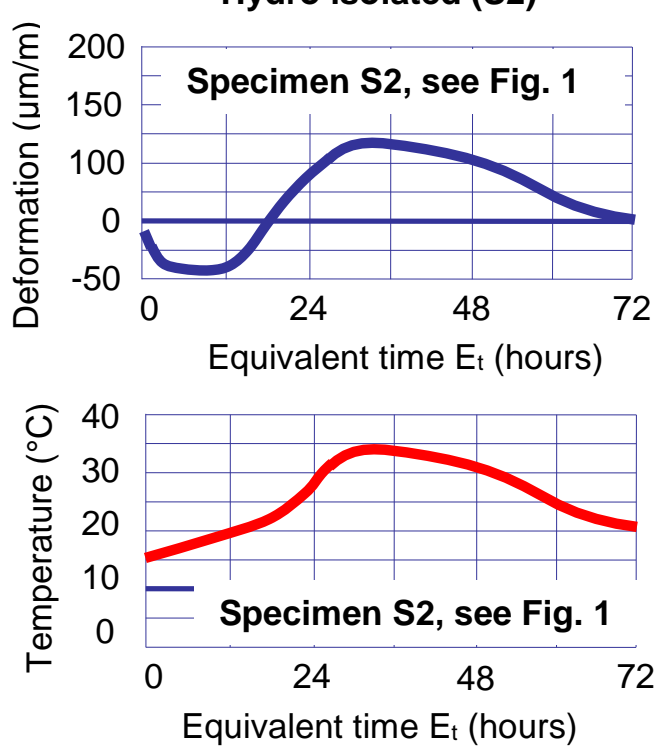

$$
\operatorname{TEC}(E t)=\frac{\Delta \varepsilon(E t)}{\Delta T(E t)}=\frac{\varepsilon_{1}(E t)-\varepsilon_{2}(E t)}{T_{1}(E t)-T_{2}(E t)}
$$

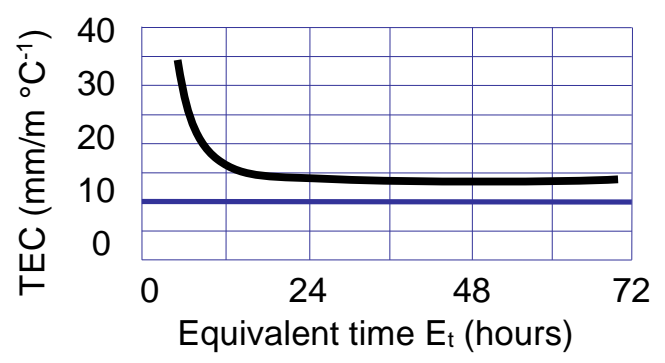

Figure 7 Separation of TEC through measurements on differently cured specimens (see Figure 1 and 2) 

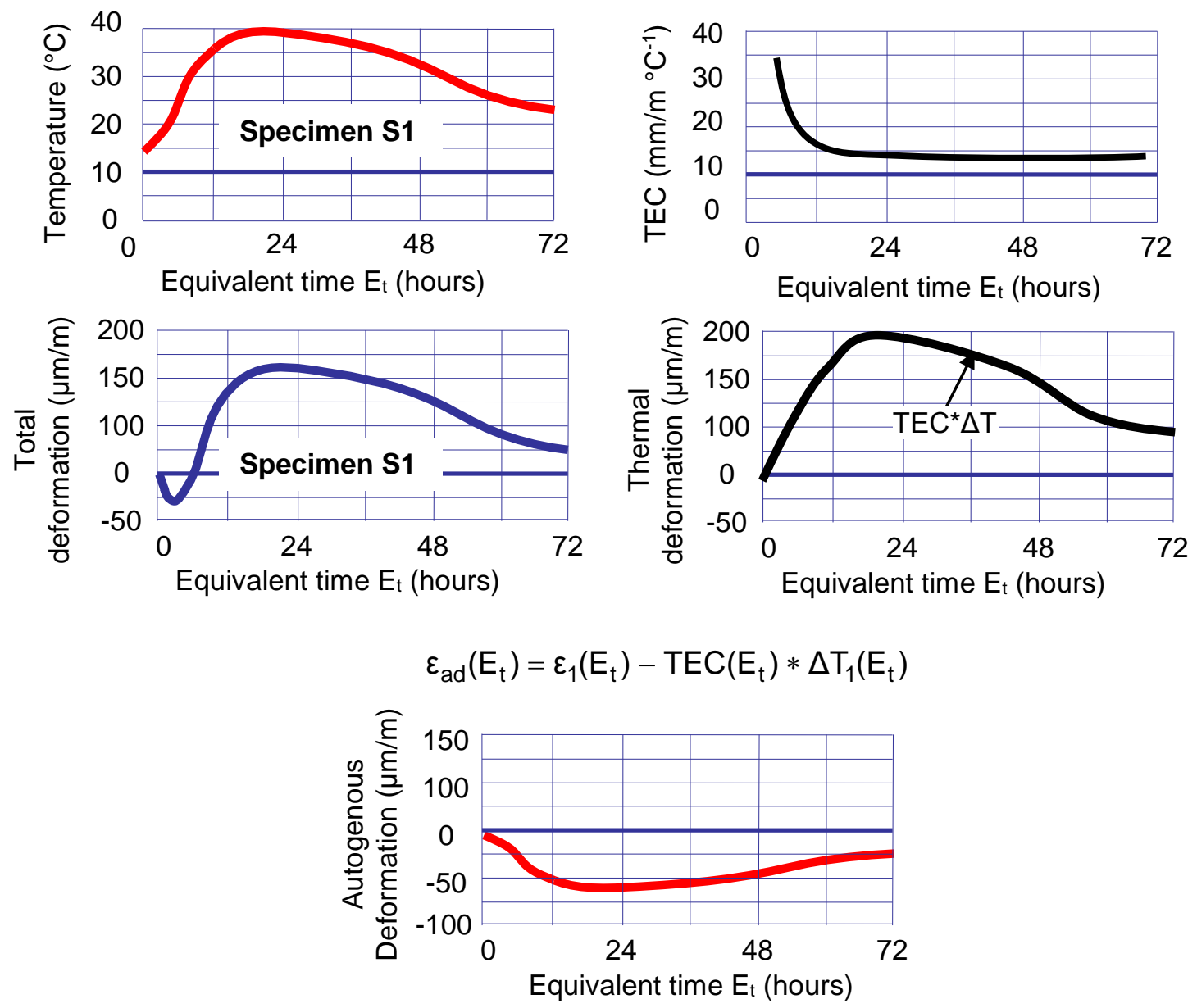

Figure 8 Separation of AD through measurements on differently cured specimens, see Figure 1 and Figure 2

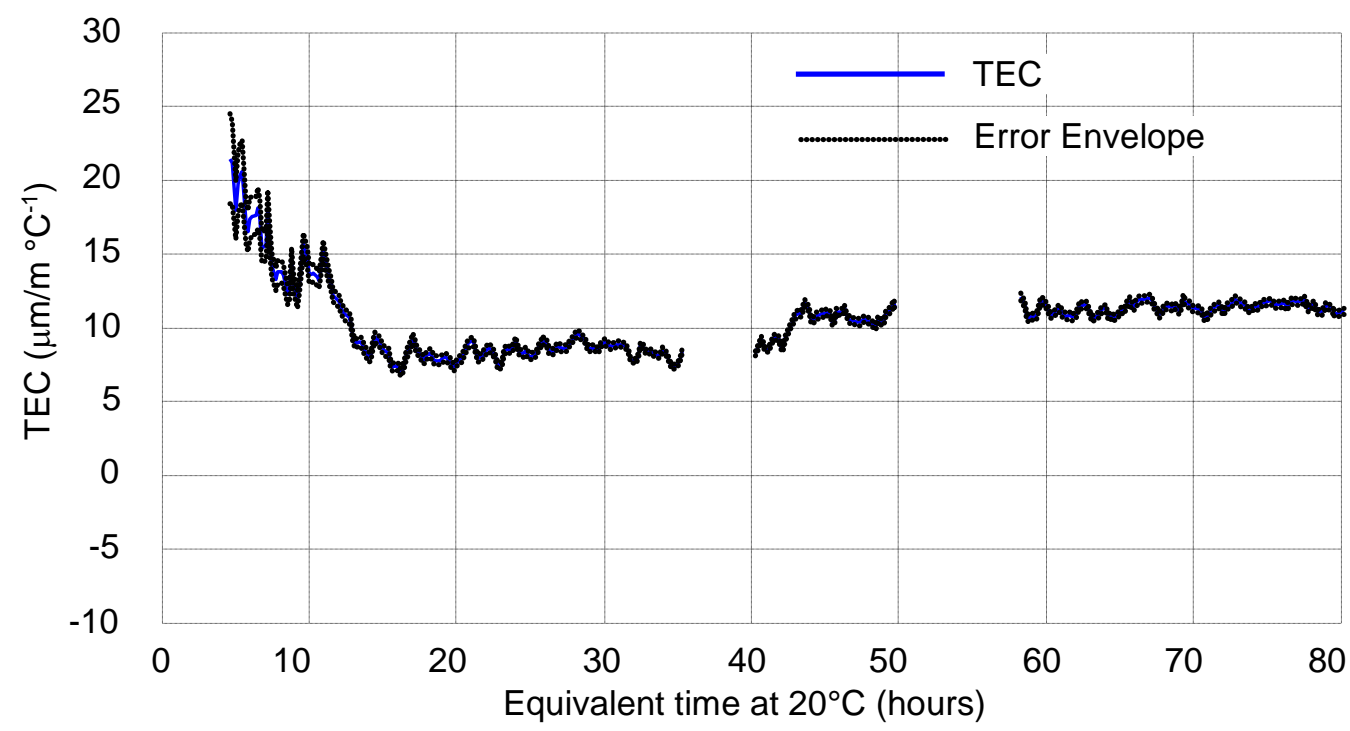

Figure 9 Thermal expansion coefficient (TEC), Test 1 


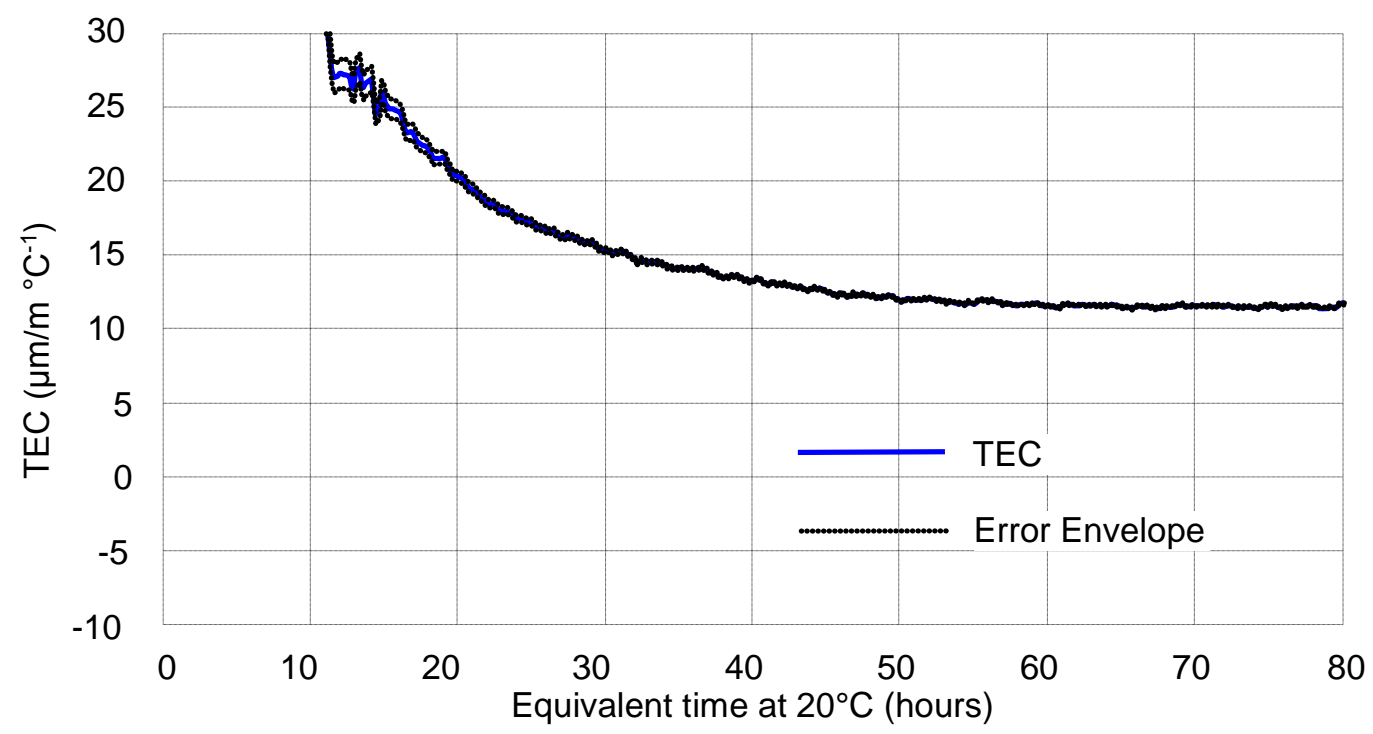

Figure 10 Thermal expansion coefficient (TEC), Test 2

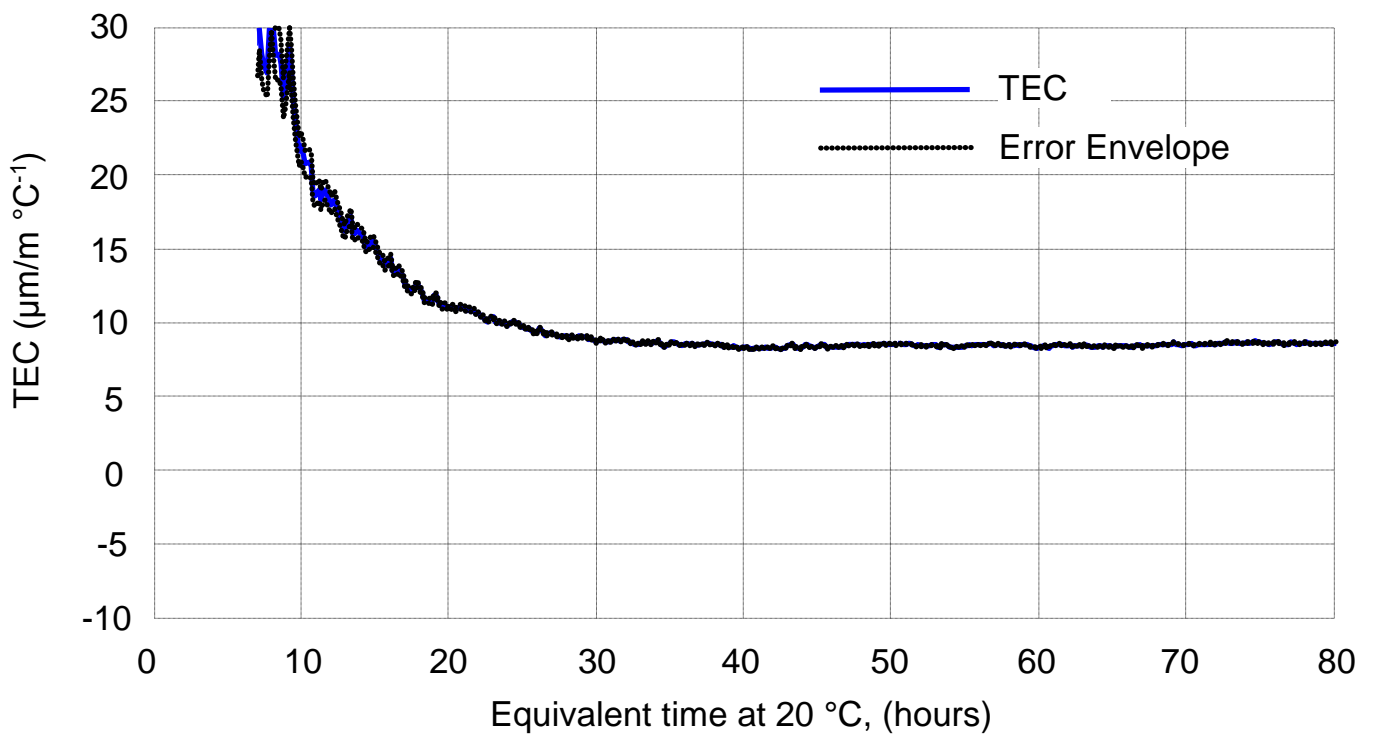

Figure 11 Thermal expansion coefficient (TEC), Test 3 


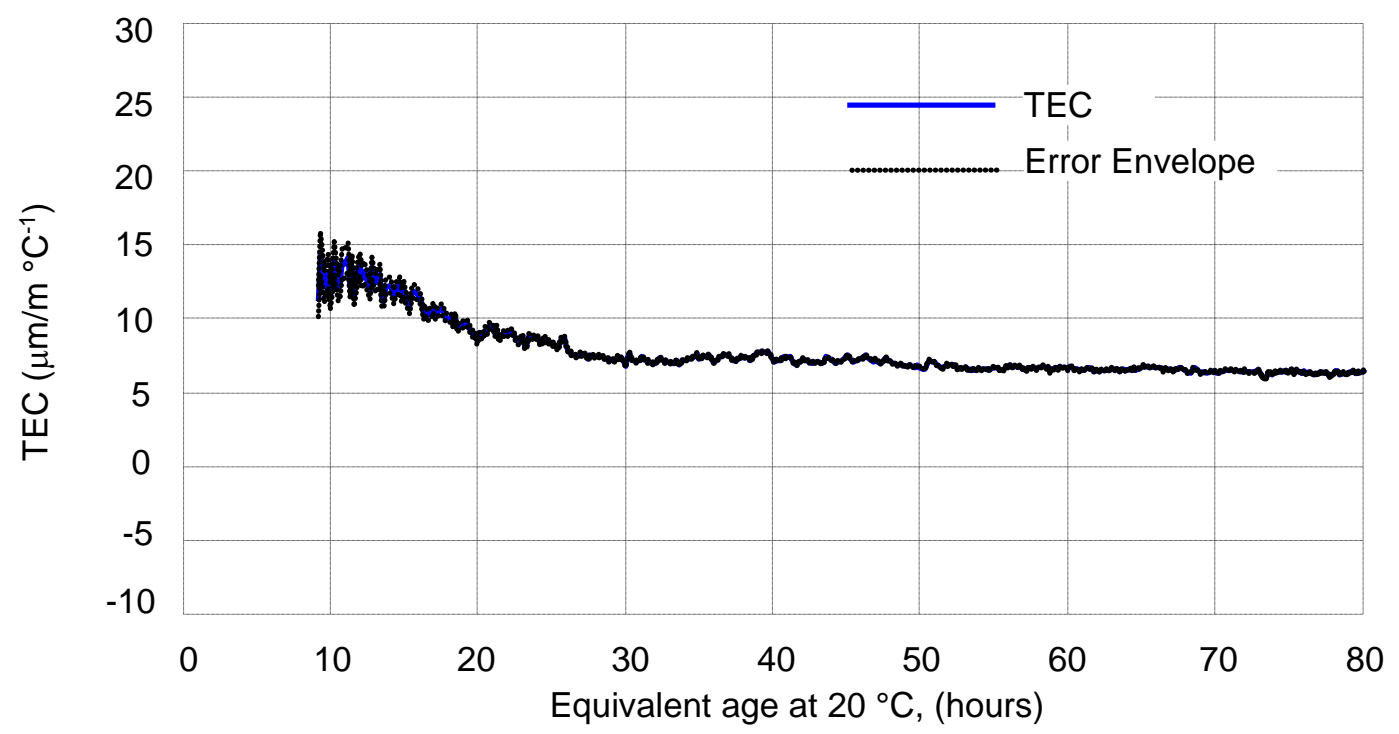

Figure 12 Thermal expansion coefficient (TEC), Test 4

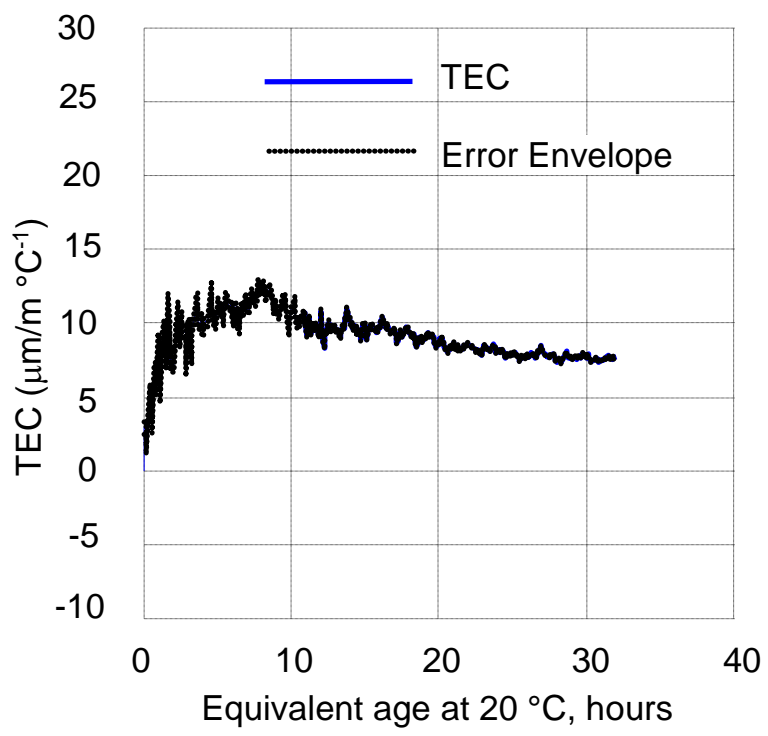

Figure 13 Thermal expansion coefficient (TEC), Test 5 


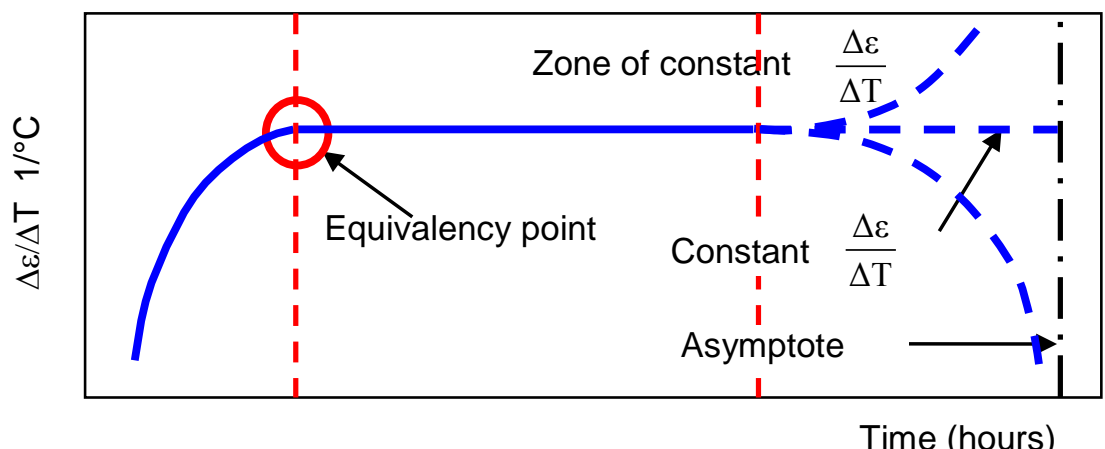

Figure 14 Predicted shape of the $\frac{\Delta \varepsilon}{\Delta T}$ curve

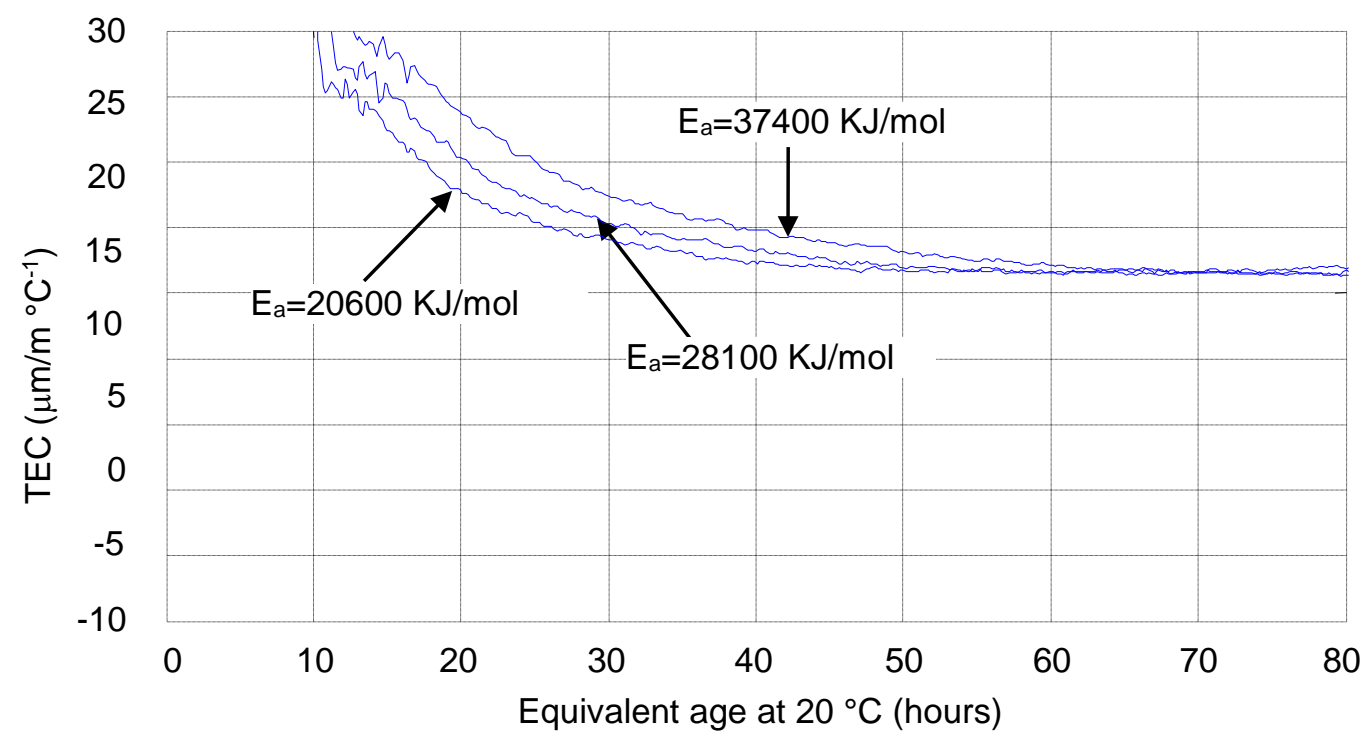

Figure 15 Effect of activation energy variation on the thermal expansion coefficient, Test 2 


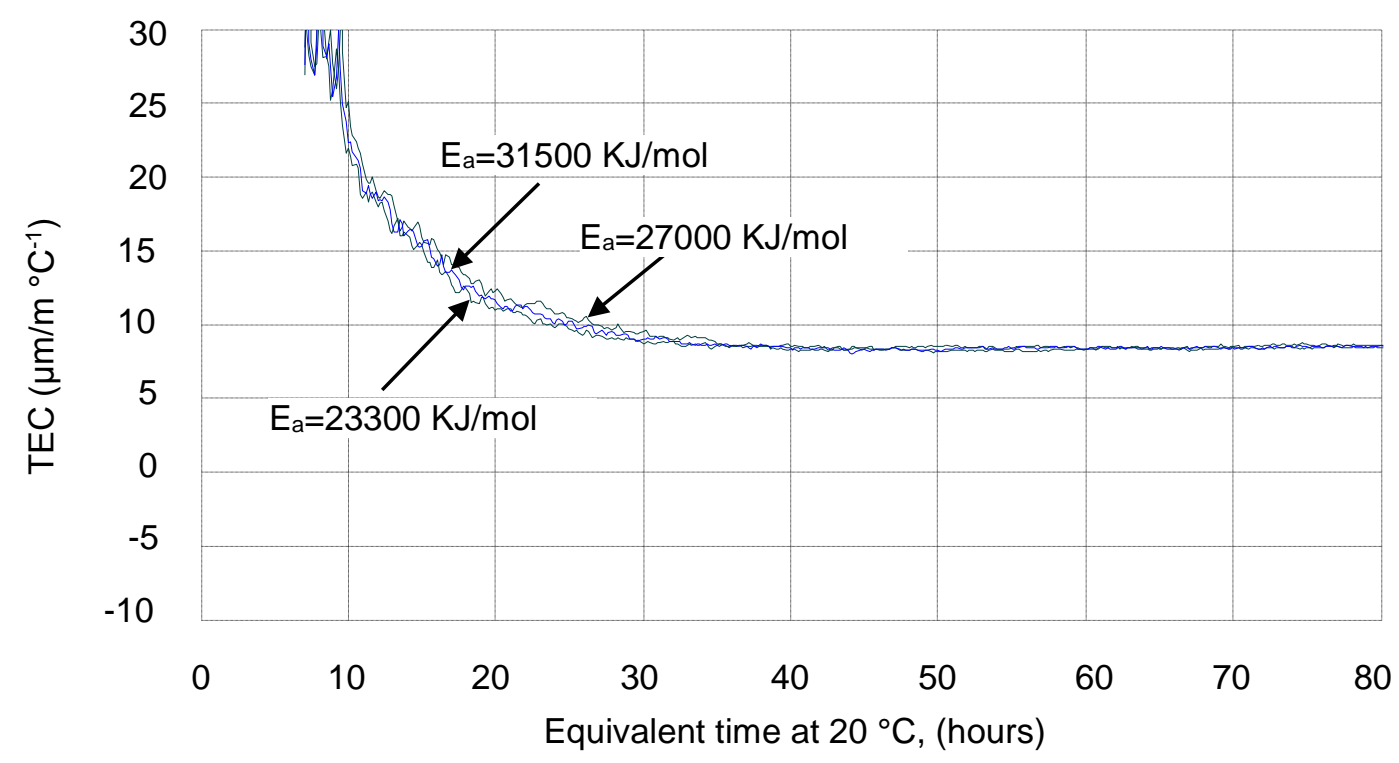

Figure 16 Effect of activation energy variation on the thermal expansion coefficient, Test 3

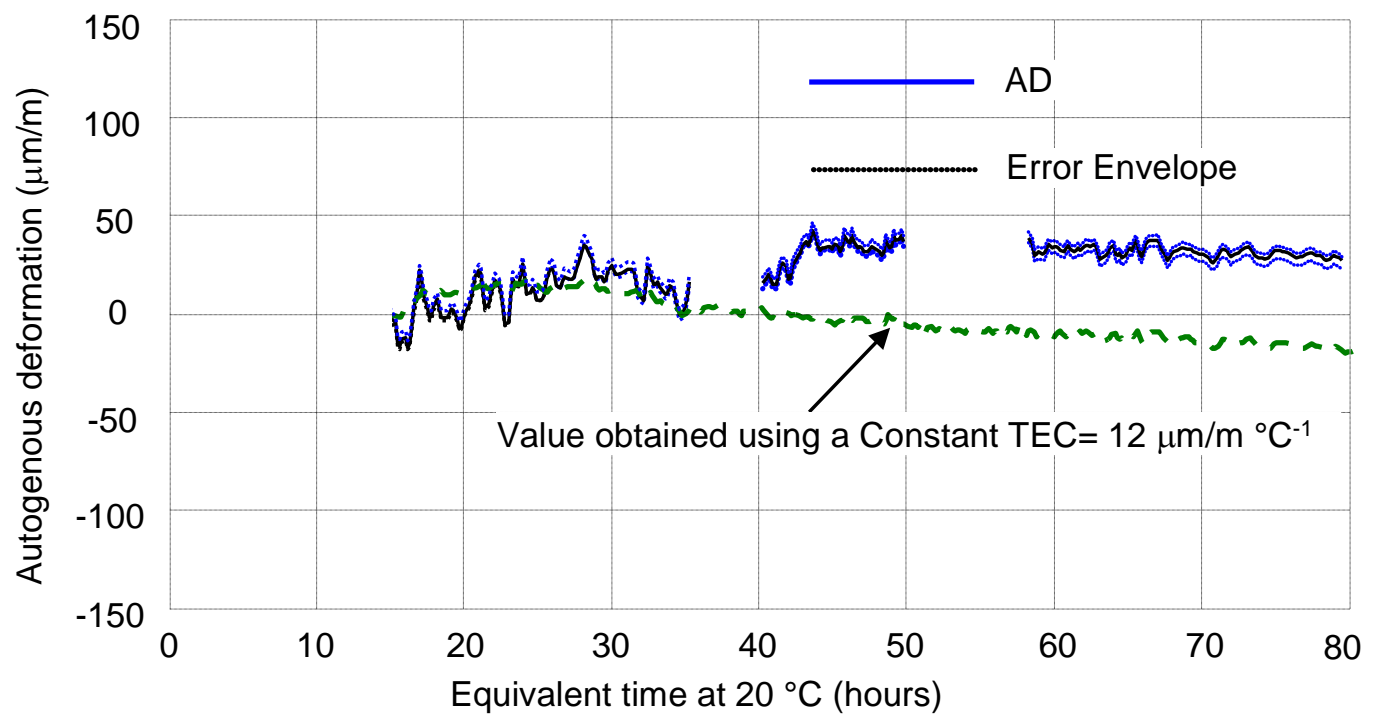

Figure 17 Autogenous deformation, Test 1: positive values are contractions. 


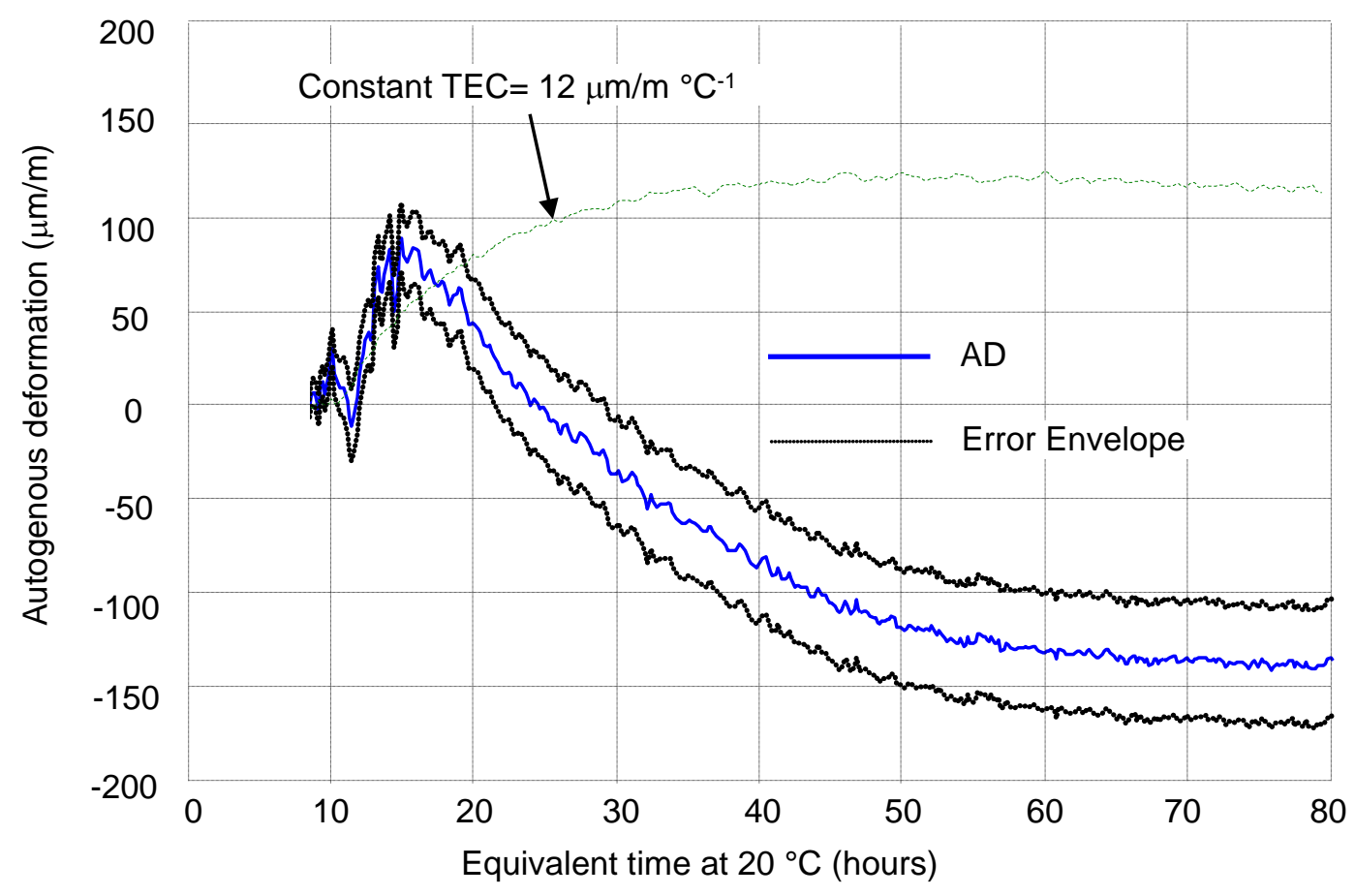

Figure 18 Autogenous deformation, Test 2: positive values are contractions

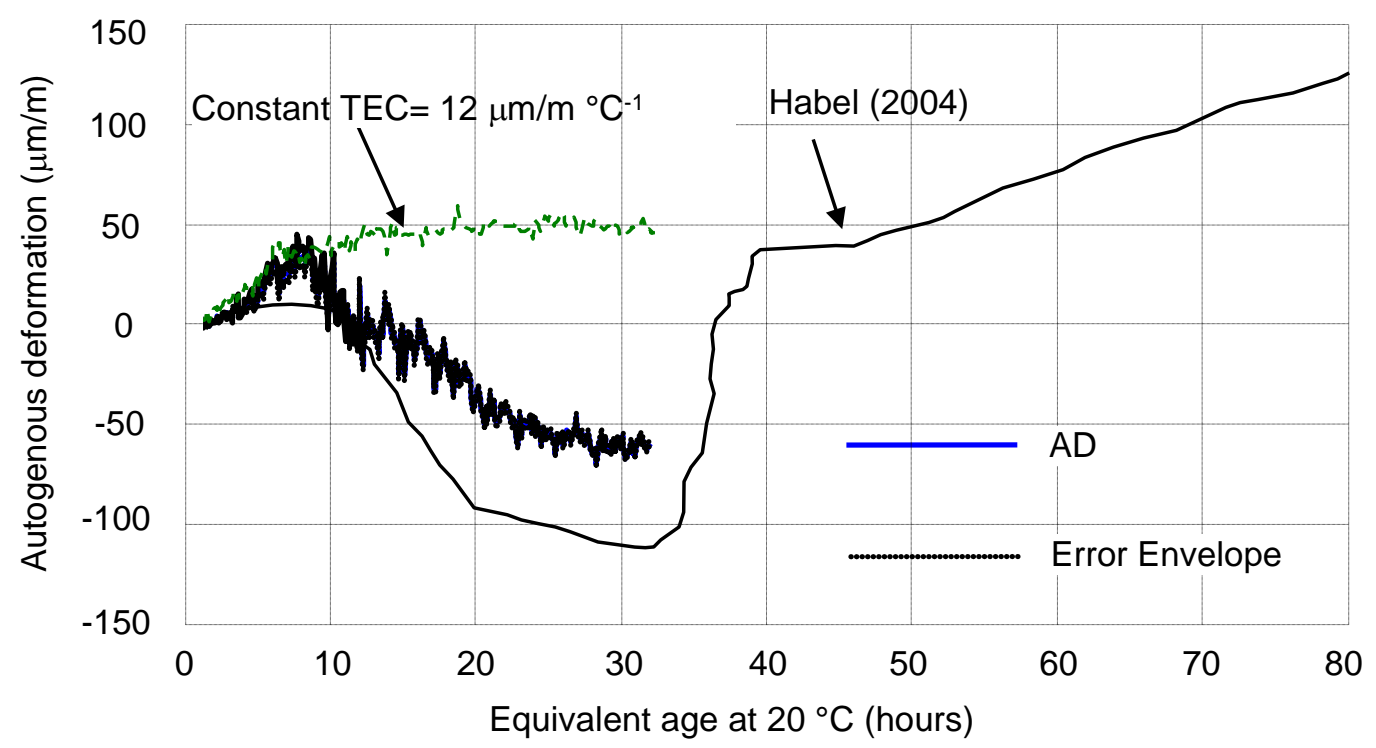

Figure 19 Autogenous deformation, Test 5: positive values are contractions 


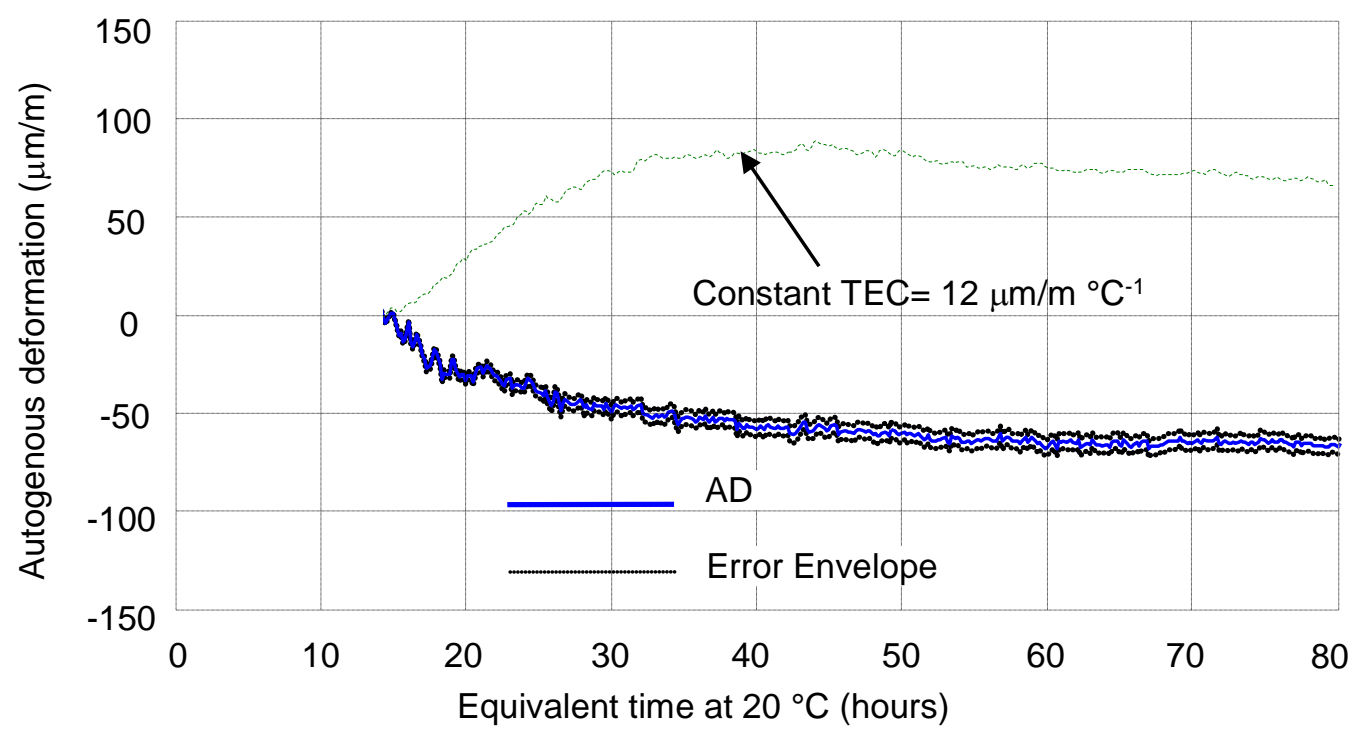

Figure 20 Autogenous deformation, Test 3: positive values are contractions

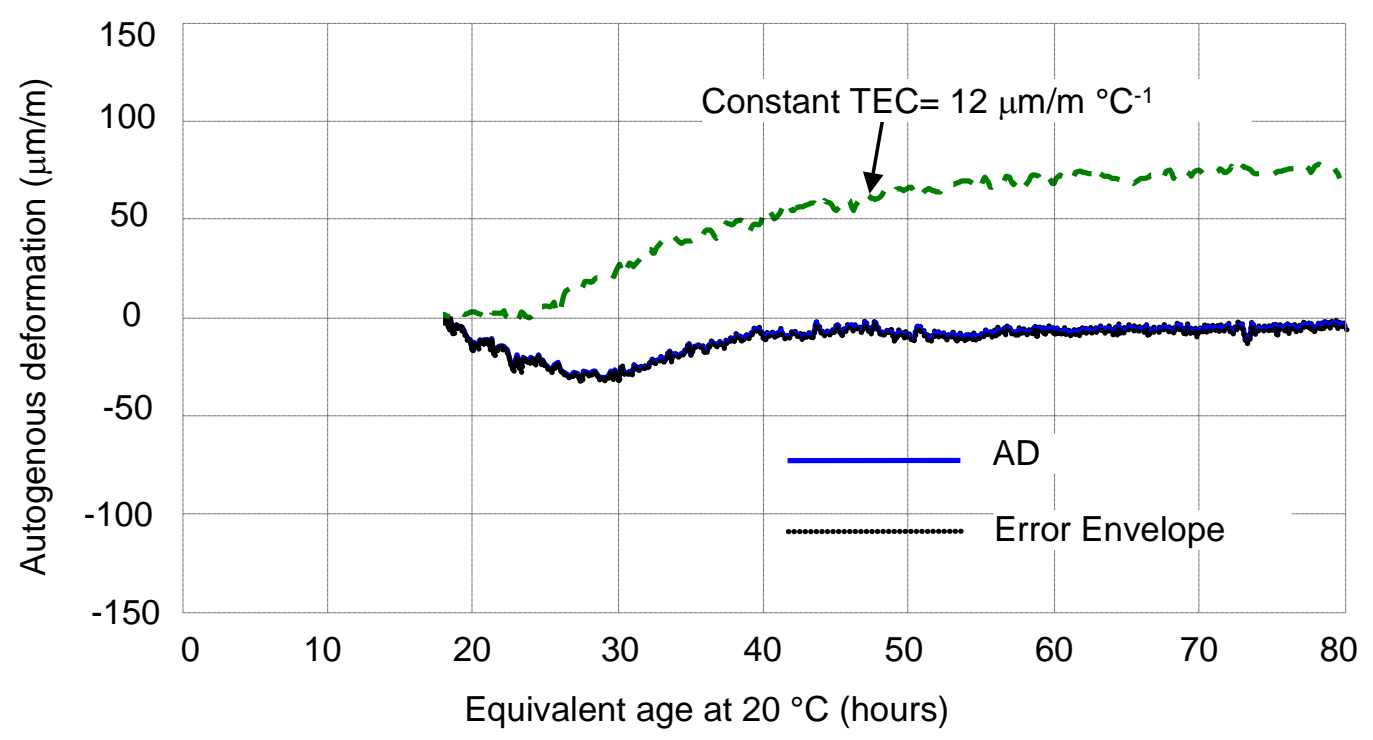

Figure 21 Autogenous deformation, Test 4: positive values are contractions 


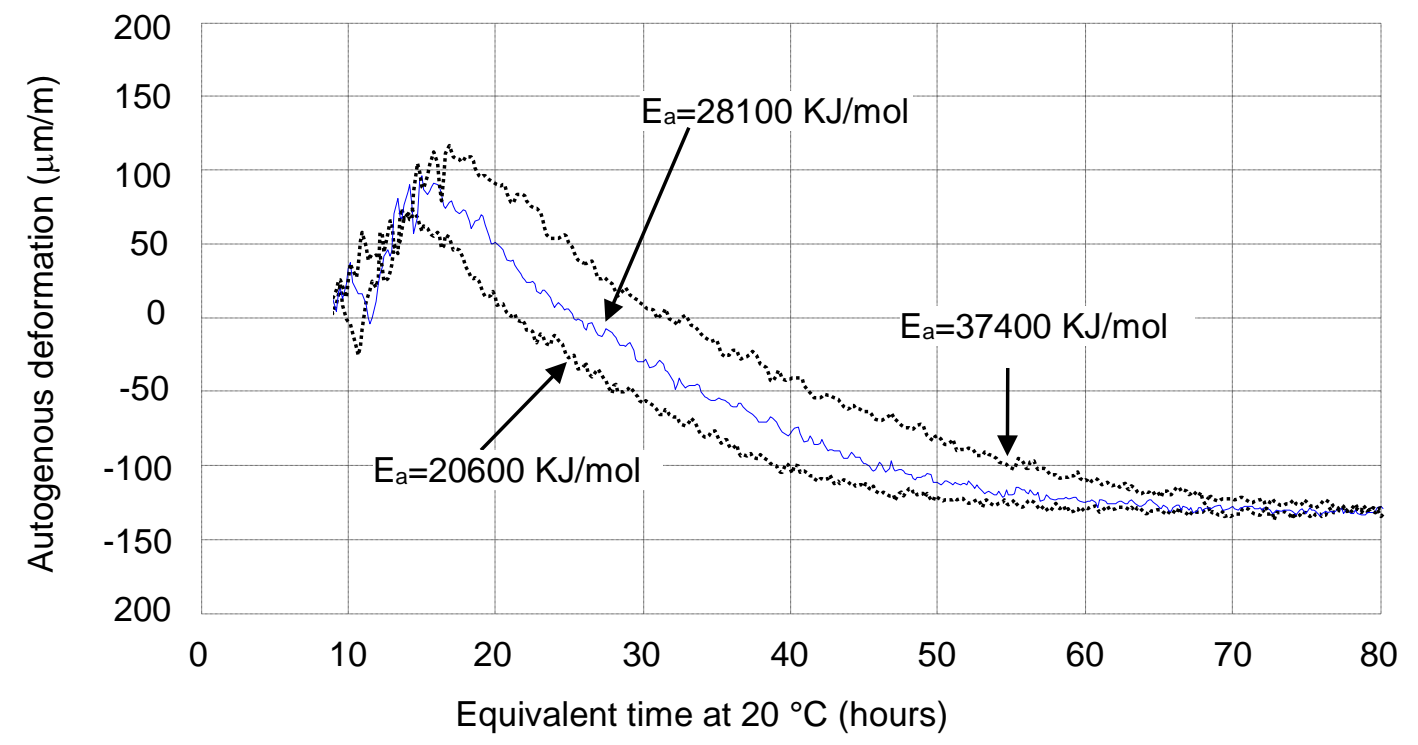

Figure 22 Autogenous deformation for three activation energies, Test 2: positive values are contractions

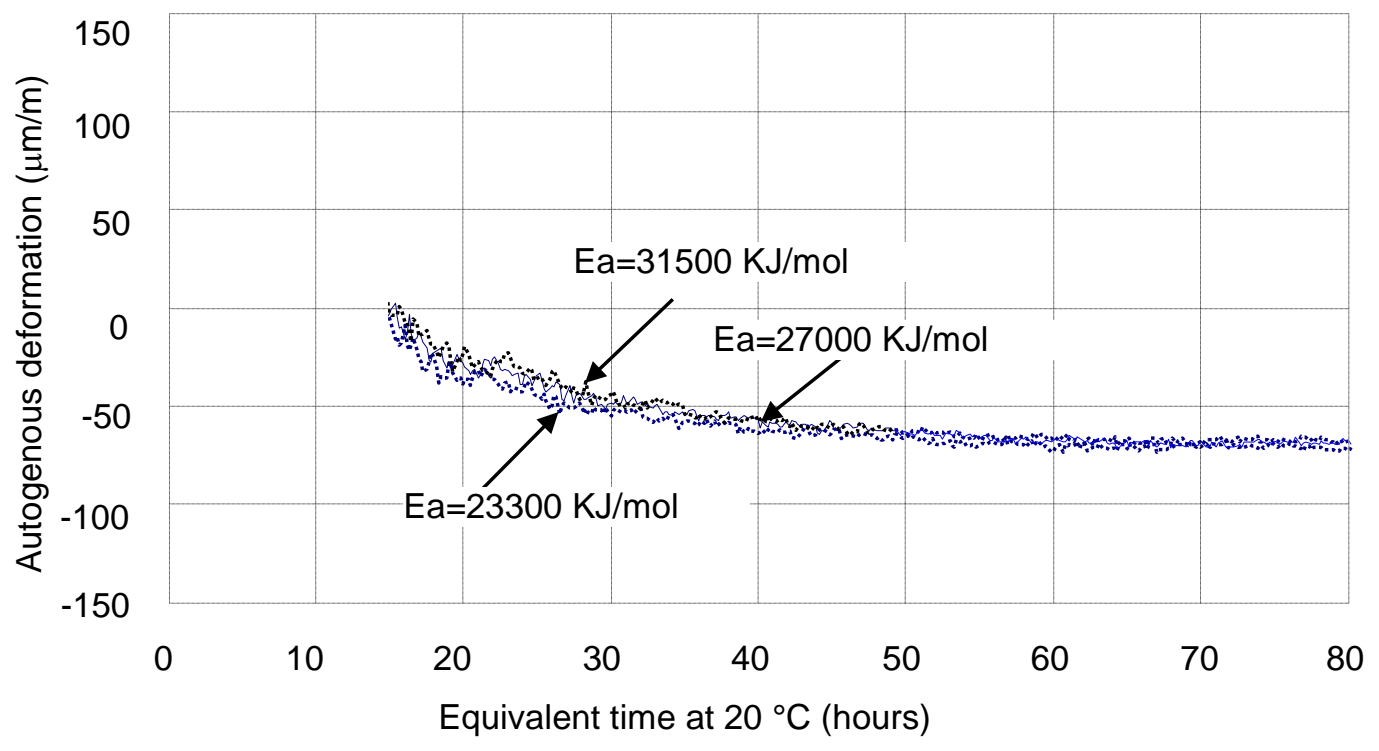

Figure 23 Autogenous deformation for three activation energies, Test 3: positive values are contractions 
Table 1 Characteristics of sensor casing

\begin{tabular}{|c|c|c|c|c|}
\hline \multirow[b]{2}{*}{ Test number } & \multicolumn{4}{|c|}{ Sensor casing } \\
\hline & Gauge length & Material & Surface & $\begin{array}{c}\text { Cross section } \\
\text { (diameter * wall thickness) }\end{array}$ \\
\hline $1,2,4$ & 800 mm & Stainless steel & smooth & $\varnothing 8 \mathrm{~mm} * 1.5 \mathrm{~mm}$ \\
\hline 3 & $800 \mathrm{~mm}$ & Stainless steel & ribbed & $\varnothing 10 \mathrm{~mm} * 2.5 \mathrm{~mm}$ \\
\hline 5 & $450 \mathrm{~mm}$ & Stainless steel & smooth & $\varnothing 2.5 \mathrm{~mm}$ * $0.5 \mathrm{~mm}$ \\
\hline
\end{tabular}

Table 2 Mix-design test 1-6

\begin{tabular}{|c|c|c|c|c|c|}
\hline & Test 1 & Test 2 & Test 3 & Test 4 & Test 5* \\
\hline $\begin{array}{l}\text { Water/cement } \\
\text { Ratio }\end{array}$ & 0.45 & 0.45 & 0.48 & 0.48 & 0.18 \\
\hline Cement type & $\begin{array}{l}\text { CEM II / A- } \\
\text { LL } 42.5 \text { R }\end{array}$ & $\begin{array}{l}\text { CEM I } \\
42.5 \mathrm{R}\end{array}$ & $\begin{array}{c}\text { CEM } \\
\text { III/A 32,5 } \\
\text { N }\end{array}$ & $\begin{array}{l}\text { CEM II/ } \\
\text { A-LL } 32.5 \\
\quad \text { R }\end{array}$ & $\begin{array}{c}\text { CEM I 52,5 N } \\
\text { HTS }\end{array}$ \\
\hline Cement quantity & $\begin{array}{c}325 \\
\mathrm{Kg} / \mathrm{m} 3\end{array}$ & $\begin{array}{c}350 \\
\mathrm{Kg} / \mathrm{m} 3\end{array}$ & $\begin{array}{c}360 \\
\mathrm{Kg} / \mathrm{m} 3\end{array}$ & $\begin{array}{c}360 \\
\mathrm{Kg} / \mathrm{m} 3\end{array}$ & $1051.1 \mathrm{Kg} / \mathrm{m} 3$ \\
\hline $\begin{array}{l}\text { Superplasticizer } \\
\% \text { cement weigth }\end{array}$ & $0.9 \%$ & $0.8 \%$ & $0.8 \%$ & $0.8 \%$ & $(35.1 \mathrm{Kg} / \mathrm{m} 3)$ \\
\hline $\begin{array}{l}\text { Air Entrainer } \\
\text { \% cement weigth }\end{array}$ & $0.1 \%$ & - & - & - & - \\
\hline Aggregate & $\begin{array}{l}\text { 0-32 mm } \\
\text { Hüttwang } \\
\text { en }\end{array}$ & $\begin{array}{c}0-32 \\
\text { mm } \\
\text { Sergey }\end{array}$ & $\begin{array}{c}0-32 \\
\text { mm } \\
\text { Sergey }\end{array}$ & $\begin{array}{c}0-32 \\
\text { mm } \\
\text { Sergey }\end{array}$ & $\begin{array}{l}0-4 \text { mmSand } \\
\text { of } \\
\text { Fontainebleau }\end{array}$ \\
\hline Silica fume & - & - & - & - & $\begin{array}{c}273.3 \mathrm{Kg} / \mathrm{m} 3 \\
\text { from } \\
\text { zirconium } \\
\text { industry }\end{array}$ \\
\hline Steel fibre & - & - & - & - & Yes* \\
\hline $\begin{array}{l}\text { Maximum } \\
\text { temperature } \\
\text { difference }\end{array}$ & $5^{\circ} \mathrm{C}$ & $15^{\circ} \mathrm{C}$ & $14.5^{\circ} \mathrm{C}$ & $21.6^{\circ} \mathrm{C}$ & $14.5^{\circ} \mathrm{C}$ \\
\hline \multicolumn{6}{|c|}{ *Further detail on the mix-design of this test: [29] } \\
\hline
\end{tabular}


Table 3 Final setting times (initial time $t_{0}$ ) for Tests 1-5

\begin{tabular}{ccc} 
Test & $\alpha c r(\%$ of Degree of reaction) & Setting times (hours) \\
\hline 1 & $18 \%$ & 15.1 \\
2 & $18 \%$ & 9.1 \\
3 & $19.2 \%$ & 14.5 \\
4 & $12.5 \%$ & 18.9 \\
5 & $4.7 \%$ & 1.35
\end{tabular}

